\title{
Endogenous Sources of Volatility in Housing Markets: The Joint Buyer-Seller Problem
}

\author{
Elliott Anenberg Patrick Bayer \\ Board of Governors of Duke University \\ the Federal Reserve \\ System
}

December 5, 2014

ERID Working Paper Number 141

This paper can be downloaded without charge from the Social

Science Research Network Electronic Paper Collection:

http://ssrn.com/abstract=2553958

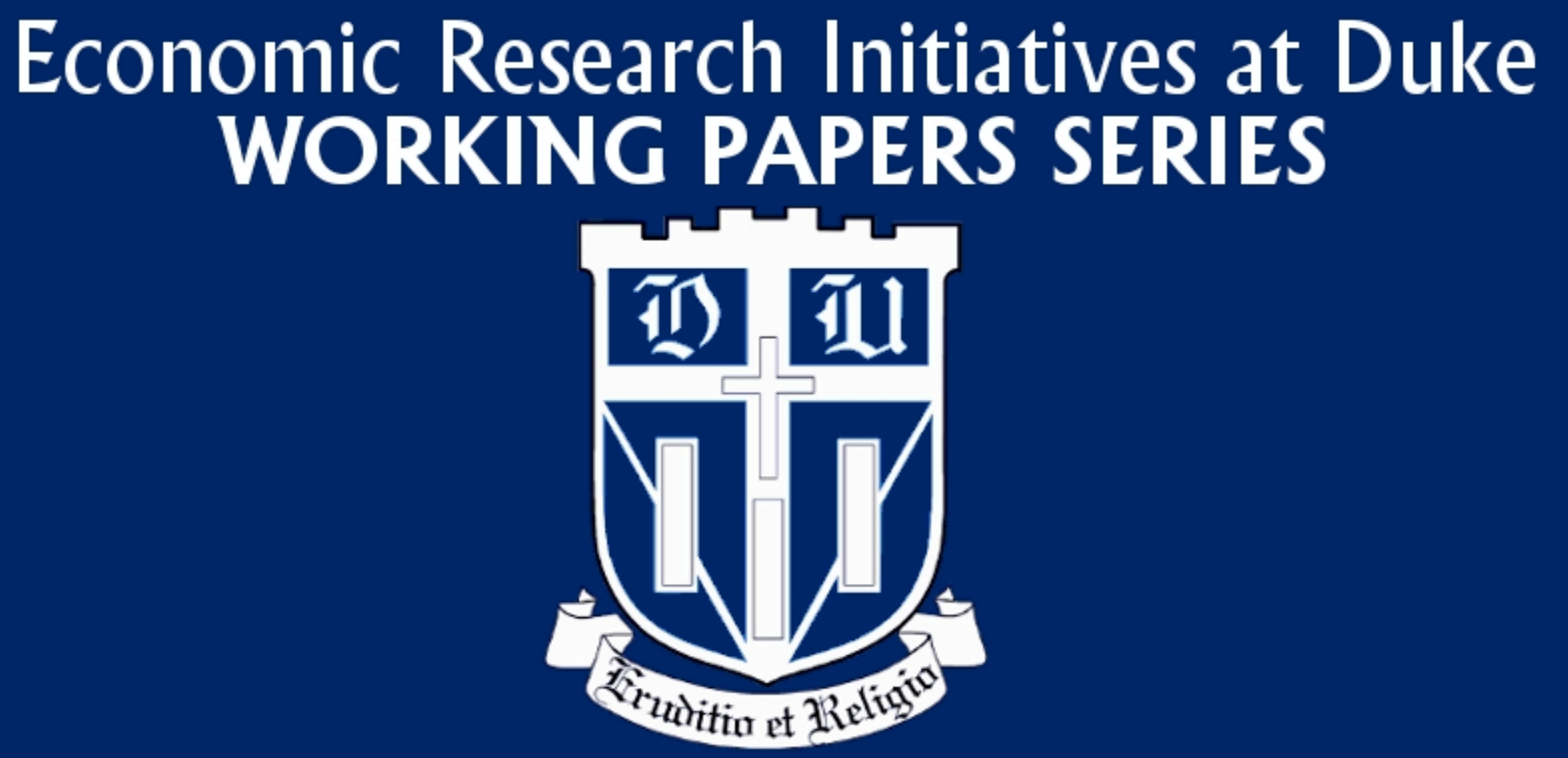




\title{
Endogenous Sources of Volatility in Housing Markets: The Joint Buyer-Seller Problem*
}

\author{
Elliot Anenberg ${ }^{\dagger}$ and Patrick Bayer ${ }^{\ddagger}$
}

December 5, 2014

\begin{abstract}
This paper presents new empirical evidence that internal movement - selling one home and buying another - by existing homeowners within a metropolitan housing market is especially volatile and the main driver of fluctuations in transaction volume over the housing market cycle. We develop a dynamic search equilibrium model that shows that the strong pro-cyclicality of internal movement is driven by the cost of simultaneously holding two homes, which varies endogenously over the cycle. We estimate the model using data on prices, volume, time-on-market, and internal moves drawn from Los Angeles from 1988-2008 and use the fitted model to show that frictions related to the joint buyer-seller problem: (i) substantially amplify booms and busts in the housing market, (ii) create counter-cyclical build-ups of mismatch of existing owners with their homes, and (iii) generate externalities that induce significant welfare loss and excess price volatility.
\end{abstract}

${ }^{*}$ The analysis and conclusions set forth are those of the authors and do not indicate concurrence by other members of the research staff or the Board of Governors. We thank Steven Laufer, Plamen Nenov, and seminar and conference participants at AEA Meetings, Econometric Society Meetings, Bank of Canada, UC Berkeley (Haas), CEMMAP Housing Conference, Federal Reserve Board of Governors, NY Fed, Wharton and Wisconsin for helpful comments.

${ }^{\dagger}$ Board of Governors of the Federal Reserve System, Washington DC.

${ }_{\ddagger}^{\ddagger}$ Duke University and NBER 


\section{Introduction}

The major boom and bust over the 2000s has drawn attention to the volatility of the US housing market and its implications for the broader economy. While the national scope of this most recent cycle was unusual, metropolitan and regional housing markets, as well those of smaller countries, exhibit cyclical behavior on a very regular basis. ${ }^{1}$ Booms and busts generally occur over protracted periods of time and are characterized by large fluctuations in price, transaction volume, and time-to-sell.

While these facts about housing cycles are well-established, explanations for their size and duration are not as obvious. Several studies have shown that movements in fundamentals like income, wages, and rents are not large enough to explain the observed fluctuations in house prices (see Head et al. [2014] and Case and Shiller [1989]). Excess housing price volatility is perhaps even more puzzling when one considers that a large fraction of transactions consist of homeowners moving within a metro area. Even if aggregate volatility is driven by fluctuations in external demand - from new migrants or first-time home buyers - one might expect the supply and demand for housing by "internal movers" selling one house and buying another at about the same time to be less sensitive to the price level and, therefore, a stabilizing force on the local market. Yet, in this paper, we will argue that the timing of the buying and selling decisions of these internal movers has exactly the opposite effect, greatly amplifying price fluctuations over the cycle rather than smoothing them.

We begin the paper by using detailed records on the universe of transactions in the Los Angeles metropolitan area from 1992-2008 to establish a series of new empirical facts about the nature of housing transactions over the cycle. Following homeowners as they buy and sell houses, we first show that internal transaction volume is incredibly volatile and indeed much more pro-cyclical than external volume. ${ }^{2}$ In particular, internal transaction volume at the peak of the boom in 2003-2005 is three times greater than in the preceding trough in 1993 and four times greater than in the subsequent trough in 2008, while external transaction volume varies in a much more narrow band. As a result, the fraction of homes sold by

\footnotetext{
${ }^{1}$ See Burnside et al. [2011] for empirical evidence.

${ }^{2} \mathrm{An}$ internal transaction is defined as one in which the seller buys another property within the metro area. An external transaction is defined as one in which the seller does not.
} 
internal movers is highly pro-cyclical, ranging from a low of 20 percent in the trough years to over 40 percent in the peak years. We demonstrate that similar patterns hold for internal transaction volume in various volatile housing markets across the country ${ }^{3}$ and that the substantial volatility of internal movement over the cycle holds for households with both low and high loan-to-value ratios. ${ }^{4}$

To gauge the economic and welfare implications of the volatility of internal movement, we develop and estimate a dynamic equilibrium search model in which the complementarity of internal movers' buying and selling decisions has the potential to amplify fundamental cyclical forces. Our framework is a simple search model in the spirit of Mortensen and Pissarides [1994] and Pissarides [2000], in which some agents in the economy (internal movers) are actively searching on both sides of the market as buyers and sellers simultaneously. ${ }^{5}$ The novel features of our model are (i) that the decision of internal movers to buy before selling, or vice versa, is endogenous and (ii) that the consumption value of holding two homes simultaneously is less than the sum of the values of residing in each property individually (e.g., a household gets little consumption value from holding a second house empty while awaiting a suitable buyer). In the model, an exogenous mismatch shock provides the impetus for homeowners to move or exit the metropolitan area. The fundamental source of equilibrium volatility is the exogenous fluctuation in external demand to purchase a home in the metropolitan area housing market.

We estimate the model using data on prices, volume, time-on-market (TOM), and internal moves drawn from our Los Angeles sample. The estimated model fits the equilibrium comovements of these variables, the level of price volatility, and the new empirical facts that we document related to internal movement over the cycle very well.

In the estimated model, the attractiveness of buying-before-selling varies endogenously

\footnotetext{
${ }^{3}$ We show internal movement patterns for MSAs outside Los Angeles using the FRBNY/Equifax Consumer Credit Panel data.

${ }^{4}$ As we discuss in more detail in Section 2, volatility in the internal movement of households with high LTVs may also be related to lock-in effects of equity constraints, while such considerations should not play a role for households with substantial equity remaining in their homes (low LTVs).

${ }^{5}$ Other classic search markets, such as labor or retail markets, are characterized by the presence of a distinct set of agents on each side of the market.
} 
over the cycle in a way that amplifies boom-bust episodes and contributes to the procyclicality of internal movement. To see how, consider a "buyer's market" in which prices are declining and time-to-sell is high. In these market conditions, existing homeowners are especially unwilling to buy before selling. Such an action would put the household in a position of owning two assets declining in value - but only receiving the consumption benefits from one of them - in a market in which houses are generally taking a long time to sell. Collectively, as existing owners hold out to sell before purchasing, internal transaction volume slows considerably, further cooling the market. Over time, the pool of households mismatched with their homes builds and when the market begins to heat up again, these mismatched households are able to move at a faster pace.

We conduct two counterfactual simulations to show how the presence of agents simultaneously active on both sides of a search market affects market volatility. In the first simulation, we assume that all agents exit the metropolitan area upon selling their home so that all selling decisions are made without regard to buyer market conditions. This simulation distinguishes the role of basic search and matching frictions from the role of the joint buyer-seller problem in driving market volatility. Relative to a setting in which just search and matching frictions operate, the results imply that the joint buyer-seller problem increases the volatility of transaction volume and time on market by about 10 percent and more than doubles the price volatility.

The increase in price volatility associated with the joint buyer-seller problem is directly related to the effective cost of holding two homes simultaneously, which, not surprisingly, is estimated to be quite high. We show this with a second counterfactual simulation that re-introduces the joint buyer-seller problem, but allows homeowners to realize more of the consumption benefits from a second home, so that they are more willing to buy before selling in equilibrium. When the effective cost of holding two properties is small enough (as might be the case if a short-term tenant were available), we demonstrate that aggregate price and volume volatility can, in fact, be lower than in the first counterfactual simulation. In this case, internal demand helps to dampen fluctuations in external demand - e.g., when there is a negative shock to the pool of external buyers, demand from internal movers rises because buying conditions are favorable. When the cost of owning two homes is higher, however, 
a drop in external demand leads to a decline in internal demand as internal movers are reluctant to buy until they have sold. At the parameters that best fit the data, this thin market effect dominates the smoothing effect, and the joint buyer-seller problem leads to a substantial increase in price volatility.

We close the paper by considering the welfare consequences of a policy intervention that lowers aggregate volatility by reducing volatility in the fraction of homes sold by internal movers. The policy induces substantially lower volatility by subsidizing the cost of remaining on the market for sellers who have high holding costs according to the estimated model i.e. internal movers who hold two homes and external sellers. We constrain the policy to be revenue neutral, and so we also impose a transaction tax to offset the cost of the subsidies. We find that the policy increases discounted lifetime utility by an equivalent variation of $\$ 4200$ per transaction. Since our model does not account for the interactions between the housing market and the broader economy and since buyers and sellers in our model are assumed to be risk neutral, this welfare estimate abstracts from the potentially large welfare benefits that accrue directly from the substantially reduced volatility. The welfare gains that we estimate arise from improved efficiency of matches between buyers and homes, suggesting that the sources of excess volatility in internal movement that are at the heart of this paper generate sizable welfare losses that extend beyond the direct effects of reduced volatility.

Our paper contributes to a growing literature starting with Wheaton [1990] that applies search theory to housing markets. From a methodological perspective, our paper extends the existing housing search literature by developing and estimating a dynamic equilibrium model with endogenous cycling. The vast majority of the existing literature selects parameter values to convey the broad intuition of the model's predictions (e.g. Krainer [2001],NovyMarx [2009]) or calibrates the model based on steady state predictions. While some recent papers consider the non-steady state dynamics of their models, we are not aware of any other papers in the housing search literature that fits the model using the dynamics of the key market variables in the data, as we do. In this respect, our empirical approach is related to Shimer [2005] and Robin [2011] in the labor search literature, which estimate models using the dynamics of unemployment, wages, and vacancies. From an empirical perspective, we contribute to the growing literature on the causes and consequences of housing market 
cycles by highlighting a new mechanism - the joint buyer-seller problem - that is capable of matching the key stylized facts about equilibrium market dynamics, as well as the new facts that we document related to internal movement over the cycle. ${ }^{6}$

\section{Motivating Empirical Facts}

Before describing our model, we begin by establishing a series of new empirical facts that suggest that the dual buyer-seller roles of agents in the market may be an important source of market friction. We also summarize a few other key features of housing market dynamics that have been well-documented in the literature. These facts will both motivate the key elements of the model and serve as moments for the GMM estimator that we develop below.

\subsection{Data}

The data for this section of the paper are drawn from detailed records on the universe of housing transactions in the Los Angeles metropolitan area from January 1988-June 2009. The counties included are LA, Orange, Ventura, Riverside, and San Bernardino. Dataquick is the provider of these data. The records include precise information on the property and structure, the transaction price, the date of the transaction, and, most importantly, the names of the buyer(s) and seller(s). When spouses purchase houses jointly, both names are observed on the property record.

By matching the names of individuals who are observed to sell and buy a house within a limited time frame, we are able to follow existing homeowners as they move within the metropolitan area. We classify a transaction as an internal move if 1) the seller appears as the buyer on a different transaction and 2) the transactions are within 12 months of

\footnotetext{
${ }^{6} \mathrm{~A}$ number of recent papers emphasize alternative mechanisms that may be complementary to the joint buyer-seller problem. For example, Burnside et al. [2011] model heterogeneous expectations and social dynamics in a search environment; Head et al. [2014] focus on the interaction between an endogenous construction sector and search and matching frictions; Piazzesi and Schneider [2009] focus on the role of optimistic investors on prices in a simple search framework; and Ngai and Tenreyro [2014] focuses on increasing returns to scale in the search technology. Other related studies include Krainer [2001],Carrillo [2012], Albrecht et al. [2007],Diaz and Jerez [2013],Genesove and Han [2012],Novy-Marx [2009],Caplin and Leahy [2011].
} 
each other. ${ }^{7}$ Because of abbreviations, marriages, name changes, etc., the name match is not straightforward and some arbitrariness is introduced when determining a match quality threshold. After familiarizing ourselves with the data, we decided that an appropriate minimum criteria for a match is that the last names of the buyer(s) and seller(s) match exactly and the first three letters of the first name(s) match exactly. We verified that the main empirical facts described below are robust to alternative choices for the match quality threshold and the maximum length of the window between moves. As described below, we also use the FRBNY/Equifax Consumer Credit Panel data as a robustness check and to provide external validity.

Before examining the data on transactions and movement, it is helpful to characterize the market cycles in the LA metropolitan area over this time period. To this end, Figure 1 presents a real housing price index for the LA metropolitan area from 1988-2008, calculated using a repeat sales analysis similar to Shiller [1991]. The underlying data for this and the other figures presented in this section are shown in Table 1. The Los Angeles market experienced booms in the late 1980s and in the early 2000s. In between these booms, the market experienced a substantial bust with real housing prices falling by 45 percent from 1990-1996. Much like the US housing market as a whole, the Los Angeles metropolitan area experienced a major bust following the early 2000s boom. Figure 1 also shows transaction volume and the median TOM over the cycle. ${ }^{8}$ Like prices, transaction volume and TOM are quite volatile over time, and they are positively and negatively correlated with prices, respectively.

\subsection{Internal Movement}

As shown in Table 1 and Figure 2, internal movement is highly pro-cyclical and volatile, much more so than external transaction volume. The volume of internal transactions in-

\footnotetext{
${ }^{7}$ Unfortunately, we cannot break out total transaction volume into internal and external movement during the years before 1992 because the buyer and seller names are severely truncated in the Dataquick data for those years.

${ }^{8}$ Dataquick does not report any information about the house listing such as TOM. The TOM data presented here comes from the California Association of Realtors (CAR) for LA county. Data provided to authors by Oscar Wei, Senior Research Analyst at CAR.
} 
creased three-fold over the price run-up in the late 1990's and early 2000's, and fell by a comparable level during the most recent bust. External transaction volume was much steadier in comparison: it increased by about 50 percent during the run-up and fell by about 50 percent during the bust. Most of the pro-cyclicality of total transaction volume comes from the pro-cyclicality of internal volume. As a result, "the internal mover share" (i.e. the fraction of transactions where the seller is an internal mover) shown in Table 1 is strongly pro-cyclical and volatile, ranging from a low of 20 percent in the trough years to almost 40 percent in the peak years. ${ }^{9}$

To ensure that our results on internal movement are not unique to Los Angeles or dependent on the assumptions of our name-matching algorithm, we also examine internal movement using the FRBNY/Equifax Consumer Credit Panel data. Using these data, we can track when homeowners throughout the country move using a household id (i.e. we do not need to match names) and we can see whether they move within or outside their MSA. Owner occupancy is not observed directly but is inferred based on whether the individual has a mortgage. We find that the level of the internal mover share is comparable in the Equifax data during the years in which the two datasets overlap. In Equifax, the average internal mover share for MSAs in California between 2001-2008 is 38 percent, versus 35 percent for Los Angeles using the Dataquick data. We not only find that the internal mover share is positively correlated with the house price cycle for MSAs in California; we also find that across MSAs in the U.S., differences in the volatility of the internal mover share over time are strongly related to across MSA differences in house price dynamics, as illustrated in Appendix Figure 1. The details of the Equifax data and the analyses are discussed in Appendix A. Appendix A also discusses a third robustness check we conduct using the American Housing Survey for Los Angeles. This dataset is more limited, but it confirms our finding that most housing transactions are indeed external.

Returning to the Los Angeles housing transaction data, Figure 3 plots the distribution of sell date minus purchase date for internal movers. It is much more common for internal

\footnotetext{
${ }^{9}$ Slightly changing the definition of an internal transaction to 1) the buyer appears as a seller on a different transaction and 2) the transactions are within 12 months of each other results in essentially no change in the dynamics of the internal mover share.
} 
movers to close on the sale of their existing home before closing on the purchase of their next home; over 70 percent of the mass lies to the left of zero, inclusive. We find evidence that selling-before-buying is more common using the Equifax data as well, as described in Appendix A. An explanation for this empirical fact is that buying-before-selling temporarily puts the homeowner in a position of owning two homes, but only receiving the consumption benefits from one of the homes. Recouping the consumption value of the vacant home by renting it out for a short period of time is usually not feasible given that renters prefer predictable and longer term leases due to large moving costs. Furthermore, households may also face binding borrowing constraints that make it difficult to hold two mortgages simultaneously for a considerable length of time. Thus, the holding costs of owning two homes simultaneously are high, which discourages agents from taking this position, all else being equal. ${ }^{10}$

One prediction of a model in which the holding cost of a second home is high is that the sales price for homes sold by owners holding two positions should be lower, all else equal. The reason is that in an illiquid market, higher holding costs should translate into lower reservation prices for sellers and, therefore, lower transactions prices. Table 2 tests this prediction in the data. In particular, we estimate a regression in which the dependent variable is the difference between the log sales price and a log "predicted market" price and the regressors are dummy variables for each window of "sell date - purchase date" from Figure 3. The sample includes all internal movers, so that the comparison is between internal movers who buy and sell at various times. The log predicted market price is calculated in a first stage through a repeat sales analysis. ${ }^{11}$ The first column shows that homes sold by sellers who bought first sell for about 2 percent less than the predicted price on average. To

\footnotetext{
${ }^{10}$ Contingency clauses (i.e. agreeing to buy contingent on being able to sell) does not circumvent the cost of buying-before-selling. These contracts typically allot a finite period of time for the home to be sold, which effectively increases the holding costs of the second home.

${ }^{11}$ For each house, we apply the level of appreciation or depreciation estimated by the Case Shiller house price index for Los Angeles to the previous purchase price. Transactions that do not have a previous price during our sample window are excluded from the second stage regression. We also exclude transactions with extreme prices, extreme residuals from the first stage, and transactions where the previous transaction for that home was less than six months ago.
} 
the extent that our name matching algorithm commits some type 1 errors, then this estimate should be biased toward zero due to measurement error. Indeed, Appendix Table A1 shows that when we strengthen the minimum name matching criteria to reduce type 1 errors, then we find an effect that is about -3 percent. Returning to Table 2 , the second column shows that there is much less of a difference between internal movers who buy versus sell first in the price that they pay for the new home that they purchase. The theory in this case is more ambiguous. We discuss this within the context of our model in Section 4. The final column of Table 2 compares the prices received by internal sellers (not distinguished by whether they buy or sell first) relative to the prices received by external sellers. External sellers sell at a discount of 5 percent relative to internal movers, suggesting they have higher holding costs than internal sellers on average.

\subsection{Alternative Explanations for Internal Transaction Volume Over the Cycle}

The model that we develop below focuses on the high holding costs associated with two housing positions as an explanation for the pro-cyclicality of the internal mover share. A potentially important alternative or complementary explanation is that internal moves slow disproportionately during busts because homeowners looking to buy another home within the metro area lack sufficient equity to make a down payment on a new home. ${ }^{12}$ If this explanation is the primary driver of the overall pro-cyclicality in the internal mover share, then we would expect the pro-cyclicality of internal movement to be weaker among sellers with high levels of implied equity in their initial property.

Figure 4 plots the internal mover share for the unrestricted sample and the sample restricted to sellers with outstanding LTV $<80$, LTV $<60$, and LTV $<40$. We calculate the denominator of LTV (the home value) by applying a zip code level house price index

\footnotetext{
${ }^{12}$ For a theoretical treatment of the effect of equity constraints on the housing market, see Ortalo-Magne and Rady [2006], Stein [1995]. Several empirical studies have tested whether low equity affects mobility and the results are mixed (see Chan [1997], Ferreira et al. [2010], Coulson and Grieco [2013], Schulhofer-Wohl [2011]). We are not aware of any studies that directly examine whether low equity affects the propensity of a mover to buy another home in the same MSA.
} 
computed by CoreLogic to the original purchase price. Transactions that do not have a previous price during our sample window would thus be excluded altogether from Figure 4. We calculate the numerator (the outstanding loan amount) by amortizing the original loan amount, including first, second, and third mortgages, assuming a 30 year term at the prevailing market interest rate for fixed rate mortgages in the quarter of origination for the West census region. ${ }^{13}$ We do see refinances in our data, and so we are able to update the imputed mortgage balance with the actual mortgage balance and the prevailing market mortgage rate whenever a refinance occurs. As shown in Figure 4, the pro-cyclicality of the internal mover share is just as strong, if not stronger, for sellers with high levels of implied equity, suggesting that equity constraints are not driving the pro-cyclicality of the internal mover share. ${ }^{14}$

Another alternative explanation to consider is that the volatility in internal movement is driven by "flippers" who buy and sell multiple houses in a short amount of time. Bayer et al. [2011] show that flippers may be active in the housing market for a number of reasons and that their buying-selling problem is likely different from the one we focus on in this paper. Thus, we want to make sure that the main stylized facts on internal movement that we use to motivate and fit the model below are not simply driven by flippers. To this end, Figure 5 reproduces the time-series of the internal mover on a subset of the main sample, which excludes all transactions purchased by buyers who buy multiple homes within the calendar year. The figure continues to show a significant amount of volatility and pro-cyclicality in internal movement, suggesting that flippers are not driving the aggregate data on internal movement.

\footnotetext{
${ }^{13}$ The source for the interest rate data is the Freddie Mac survey. This may not be an appropriate assumption for adjustable rate mortgages. Our data do provide a flag for fixed rate or adjustable rate mortgages, and when we restrict the sample to just fixed rate loans, the results in Figure 4 are similar.

${ }^{14}$ A related potential alternative explanation is nominal loss aversion (Genesove and Mayer [2001], Engelhardt [2003], Anenberg [2011]). However, based on the existing literature, there is no reason to expect that those moving internally are disproportionately susceptible to loss aversion and so loss aversion should not explain the pro-cyclicality of internal movement.
} 


\section{Model}

\subsection{Overview}

We now develop a dynamic equilibrium model of housing market search. Our primary goal is to develop the simplest model necessary to highlight how the complementarity of buying and selling decisions affects the housing market equilibrium. To this end, we build off of the classic Diamond-Mortensen-Pissarides random search framework. Buyers and sellers in a city are searching for one another, and each matching generates an idiosyncratic match quality that describes the buyer's taste for the particular home. Some sellers are also acting as buyers (internal movers), whereas other sellers are simply looking to sell their home and exit the city (external movers). Many features of our model are standard. Prices are determined through complete information Nash bargaining over the transaction surplus. The matching function is constant returns to scale as in most of the housing search literature. This ensures that any amplification of market shocks will come from the joint buyer-seller problem and not from an assumption on the search technology such as increasing returns to scale.

Two features of the model are unique. First, the decision to buy before selling is endogenous, and, second, we allow the flow utility of being a seller to depend on whether the seller has already purchased a second home. This extension to a basic search and matching model is not trivial because it means that buyer and seller value functions can no longer be written independently. Second, our model generates endogenous cycling through shocks to the size of the pool of active searchers. This is in contrast to much - but not all - of the existing housing search models, which investigate dynamics based on a comparison of steady states. $^{15}$

\footnotetext{
${ }^{15}$ Krainer [2001] generates endogenous cycling, but only with significant fluctuations in prices when exogenous, aggregate shocks to the housing dividend are highly persistent. We generate cycling with time invariant housing dividends by allowing the search process to depend on the market tightness; market tightness plays no role in Krainer [2001] as each seller is automatically matched with one buyer each period.
} 


\subsection{Environment and Preferences}

Time is discrete. Agents discount the future at rate $\beta$. As in the discussion in Section 2, the model focuses on activity in a single housing market, which we call a city, and takes activity outside this area as exogenous. There is a fixed stock of homes in the city normalized to have measure one. This assumption is motivated by the empirical evidence that large amounts of volatility occur in cities such as Los Angeles where increases in housing supply are limited by zoning laws, land scarcity, or infrastructure constraints. ${ }^{16}$ Agents in the economy have heterogeneous preferences for these homes. In equilibrium there will be four types of homeowners. Owners can be matched with one home, mismatched with one home, matched with one home and mismatched with another, or mismatched with two homes. Preferences are set such that no other combination of homes will be owned in equilibrium.

The mismatch process works as follows. New owners always begin in the matched state. Matched homeowners then become mismatched at rate $\lambda$. A fraction $1-\pi$ of newly mismatched owners also become mismatched with the city and will exit the model economy upon selling their home. The remaining fraction, $\pi$, enter a buyer pool and search for a different home to buy while simultaneously searching to sell the home that they have become mismatched with. ${ }^{17}$

Each period, $\gamma_{t}$ non-homeowners exogenously enter the economy. The inflow process is assumed to be iid over time. Upon entering the economy, these non-homeowners enter the buyer pool and begin searching for a home to buy. Thus, the total buyer pool is comprised of (1) new entrants to the city, (2) homeowners who are currently mismatched with their home but are still matched with the city and (3) previous homeowners who are still matched with the city.

We now specify the utilities associated with each of the possible states in equilibrium. Matched agents receive a time-invariant flow utility, $\epsilon_{i}$, that is heterogenous for each agent $i$.

\footnotetext{
${ }^{16}$ See e.g. Quigley and Raphael [2005] and Glaeser et al. [2005].

${ }^{17} \mathrm{We}$ also are assuming that a matched owner and agents who become mismatched with the city receive a large negative utility from being matched with another one of the homes in the economy. Then, assuming that there are nominal fixed costs to being on the market as a buyer or as a seller, homeowners will not enter the buyer or seller pools until they are mismatched and agents who get mismatched with the city will not re-enter the buyer pool.
} 
Mismatched owners receive the constant flow utility $u_{m m}$ or $u_{m m o}$ depending on whether they are mismatched with their house or mismatched with their house and the city, respectively. Agents who own two homes, which can occur when a mismatched homeowner buys before selling, can only realize the utility benefits from one of their homes, reflecting the fact that households can only live in one home at a time. We assume that they get the benefits from the house which provides them the greater flow utility. We do, however, allow the flow utility of owning two homes to be shifted up or down by a parameter $u_{d}$. This allows for the possibility that in practice, factors outside of our model like maintenance costs, property taxes, financing constraints, or the ability to find a short-term tenant make it more or less costly to hold two positions then our structure here implies. Non-homeowners receive the flow utility, $u_{b}$. Agents who exit the economy receive the flow utility $u_{O}$.

We summarize below the six different pools of agents in the equilibrium of this economy and the flow utility associated with being in each pool ${ }^{18}$ :

- Buyers (b), $u_{b}$ : Non-homeowners searching to buy a home.

- Matched Owners $(\mathrm{m}), \epsilon_{i}$ : Agents that are matched with one home.

- Buyer-Sellers (bs), $u_{m m}$ : Agents that are mismatched with a home and have it for sale while simultaneously searching to buy a home.

- Dual Position Sellers (ms), $\epsilon_{i}-u_{d}$ : Agents that are matched with one home and mismatched with another home that is for sale.

- External Sellers (s), $u_{m m o}$ : Agents that are mismatched with a home that is for sale. These agents are also mismatched with the city and will exit the city upon sale.

- Dual Position External Sellers (ss), $u_{m m o}-u_{d}$ : Agents that are mismatched with two homes that are for sale. These agents are also mismatched with the city and will exit the city upon sale of both homes.

\footnotetext{
${ }^{18}$ We make one minor additional assumption on the mismatch process that gives us six instead of seven pools. In particular, we assume that any mismatch shock that hits dual position sellers is always one that leaves them mismatched with the city. This assumption is made for simplicity and is not important for our results given the parameter values we consider below.
} 
The total mass of agents searching to buy at any given time is then $B=b+b s$ and the total mass of agents searching to sell is $S=b s+s+m s+2 s s$. Following our definition when we investigated internal movement in the data in Section 2, we classify a home sale by a member of $b s, m s$, or $s s$ as an internal transaction; sales by members of $s$ are external transactions.

\subsection{Meetings}

A necessary condition for a house sale is a meeting between a buyer and seller. The number of meetings is determined through a matching function $M(\cdot, \cdot)$ which takes as inputs the mass of buyers, $B$, and sellers, $S$. The matching function is increasing in both its arguments, concave, and homogeneous of degree one. Buyers and sellers experience at most one match with the opposite type each period. The probability that any buyer (seller) finds a match is simply $M$ divided by the mass of active buyers (sellers). When a match does occur, given that search is random, the probability that the match is with a type $j$ seller (buyer) is just the relative frequency of type $j$ sellers (buyers) among the population of sellers (buyers).

Once a meeting between a buyer and seller occurs, the buyer and seller must decide whether to pursue the match and observe the associated match quality draw, $\epsilon$. The $\epsilon_{i}$ shock can be interpreted as the buyer's idiosyncratic taste for the particular house. It is iid across time and matches. We assume that the costs to pursuing the match are negligible; however, to keep the model tractable, we do not allow households to pursue more than one match per period. A more structural interpretation is that pursuing the match requires an investment of time (e.g. an inspection) that cannot be done more than once per period. If and only if both the buyer and the seller decide to pursue the match, $\epsilon_{i}$ and the type of match (e.g. a $b$ buyer is matched with a $s$ seller) is revealed to both the buyer and the seller.

The constraint that agents cannot pursue more than one match per period is only ever binding for members of the $b s$ pool, who are actively searching on both sides of the market, and for members of the ss pool, who have two homes for sale. In the event that an agent encounters two matches, he chooses to pursue the match that leads to the higher expected payoff. Note that conditional on encountering two matches, members of $s s$ will always be exactly indifferent over which match to pursue because the expected value of each match is 
ex-ante identical before $\epsilon$ or the type of buyer is revealed. The decision for $b s$ to pursue the match as a buyer or as a seller will vary depending on the state of the economy.

\subsection{Trade}

Trade occurs whenever the total gains from trade exceed the total gains from continued search by both parties. Below, we make these transaction thresholds explicit. If a transaction occurs, the total surplus is split among the buyer and selling according to the weights $1-\theta$ and $\theta$, respectively. Formally, this is the solution to the complete information Nash bargaining game when the bargaining power of the buyer and seller is $1-\theta$ and $\theta$. In order to achieve this allocation of the surplus, a transfer, $p^{*}$, is made from one party to the other if necessary. This transfer can be interpreted as a price.

Figure 6 summarizes the flow of agents between pools. Transitions that occur endogenously through trade are highlighted with double arrows. The remaining transitions are the result of exogenous mismatch shocks or inflow into the market. In sum, agents can become mismatched with their homes any number of times - moving within the market when this happens - until they eventually become mismatched with the market as a whole and leave the metro area.

\subsection{Timing}

In each period, the following sequence of events occurs:

1. Buyers meet sellers according to the matching technology.

2. Agents who are confronted with two meetings choose to pursue the meeting that yields the highest expected payoff.

3. Idiosyncratic match qualities and the type of buyer/seller involved in the match are revealed.

4. Bargaining and trade occurs.

5. Agents consume their flow utility. 
6. Mismatch shocks are realized.

7. Inflow into the city shocks are realized.

\subsection{Value Functions}

We now characterize the dynamic problem of each type of agent given the vector of state variables $\Omega=\left(b_{t}, b s_{t}, s_{t}, m s_{t}, s s_{t}\right)$, which characterizes the mass of agents in each pool. Note that with a fixed housing stock normalized to one, $m=1-2 m s-b s-s-2 s s$ so it is redundant to include $m$, the mass of matched homeowners, in the state space.

In presenting the value functions, we will make use of the following notation to simplify the presentation. Let $\Pi^{j, k}\left(\Omega_{t}\right)$ be the expected value of the total surplus associated with a transaction between a type $j$ buyer and a type $k$ seller conditional on the total surplus being greater than zero, multiplied by the probability that the total surplus is greater than zero. Let $d^{\text {sell }}\left(\Omega_{t}\right)$ be the policy function that maps the state of the economy into the binary choice of $b s$ to pursue a match as a seller, conditional on bs matching with both a buyer and a seller. In the Appendix, we provide a closed form for $\Pi^{j, k}\left(\Omega_{t}\right) \forall j, k$ and $d^{\text {sell }}\left(\Omega_{t}\right)$ given our parametric assumptions imposed below for estimation. Finally, we abbreviate the dependence on $\Omega_{t}$ in what follows with the subscript $t$.

\subsubsection{Matched Owners}

The expected lifetime utility of being a matched owner given match quality $\epsilon_{i}$ is

$$
V_{t}^{m}\left(\epsilon_{i}\right)=\epsilon_{i}+\beta \int_{\gamma}\left(\lambda \pi V_{t+1}^{b s}+\lambda(1-\pi) V_{t+1}^{s}+(1-\lambda) V_{t+1}^{m}\left(\epsilon_{i}\right)\right) .
$$

In words, with probability $\lambda$, the matched owner becomes mismatched and either becomes a member of $b s$ or $s$ with probability $\pi$ and $1-\pi$, respectively; with probability $(1-\lambda)$, the owner remains a matched owner, which produces the flow benefit $\epsilon_{i}$. Uncertainty is over the number of new entrants into the buyer pool, $\gamma$.

Iterating on the above expression, we can rewrite (1) as a component that depends on the match quality, $\epsilon_{i}$, and an additively separable component that does not: 


$$
\begin{aligned}
V_{t}^{m}\left(\epsilon_{i}\right) & =\frac{\epsilon_{i}}{1-\beta(1-\lambda)}+\beta \int_{\gamma}\left(\lambda \pi V_{t+1}^{b s}+\lambda(1-\pi) V_{t+1}^{s}+\right. \\
& \left.\beta(1-\lambda) \int_{\gamma}\left(\lambda \pi V_{t+2}^{s}+\lambda(1-\pi) V_{t+2}^{b s}+\ldots\right)\right) \\
& =\tilde{\epsilon}_{i}+U_{t+1}^{m}
\end{aligned}
$$

where $\tilde{\epsilon}_{i}$ has mean and variance given by:

$$
\tilde{u}_{m}=\frac{u_{m}}{1-\beta(1-\lambda)}
$$

and

$$
\tilde{\sigma}^{2}=\frac{\sigma^{2}}{(1-\beta(1-\lambda))^{2}} .
$$

\subsubsection{Buyers}

We write the expected lifetime utility of being in the $b$ pool as:

$$
\begin{array}{r}
V_{t}^{b}=u_{b}+\beta \int_{\gamma}\left(V_{t+1}^{b}+\frac{M_{t+1}}{B_{t+1}}(1-\theta)\left(\frac{m s_{t+1}}{S_{t+1}} \Pi_{t+1}^{b, m s}+\frac{s_{t+1}}{S_{t+1}} \Pi_{t+1}^{b, s}+\right.\right. \\
\left.\left.\frac{b s_{t+1}}{S_{t+1}}\left(1-\frac{M_{t+1}}{B_{t+1}}+\frac{M_{t+1}}{B_{t+1}} d_{t+1}^{s e l l}\right) \Pi_{t+1}^{b, b s}+\frac{2 s s_{t+1}}{S_{t+1}}\left(1-\frac{M_{t+1}}{2 S_{t+1}}\right) \Pi_{t+1}^{b, s s}\right)\right)
\end{array}
$$

We interpret the term within the integral as follows. If there is a match, which occurs with probability $\frac{M}{B}$, the buyer receives a share $(1-\theta)$ of the expected total surplus of the transaction conditional on the total surplus being positive $\left(\Pi^{j, k}\right)$ in addition to his outside option, $V_{t+1}^{b}$, which is to enter the next period as a buyer.

Note that the conditional expected surplus depends on the type of seller that the buyer meets. Given that search is random, the probability that the match is with a type $j$ seller is just $(j / S)$. Recall that the structure of our model only allows agents in the economy to pursue one match at a time. Therefore, if the buyer meets with a type bs or ss seller, then the probability that the meeting leads to an idiosyncratic match draw is generally less than one; that is, the $b s$ and the ss sellers may choose to pursue a different match as a buyer or as a seller, respectively. The probability that a $b s$ and $s s$ seller choose to pursue the match 
with a particular buyer is $\left(1-\frac{M_{t+1}}{B_{t+1}}+\frac{M_{t+1}}{B_{t+1}} d_{t+1}^{\text {sell }}\right)$ and $\left(1-\frac{M_{t+1}}{2 S_{t+1}}\right)$, respectively. The probability for the $b s$ seller accounts for the events where $b s$ does not match with a seller, or he does match with a seller but $d_{t+1}^{\text {sell }}=1$ so that he would not choose to pursue that match in any event. The probability for the ss seller accounts for the events where ss does not match with another buyer $\left(1-\frac{M}{S}\right)$, or he does match with another buyer put picks to pursue the match with $b\left(\frac{M}{2 S}\right)$.

\subsubsection{Dual Position Sellers}

The expected lifetime utility of being a dual position seller given match quality $\epsilon_{i}$ is

$$
\begin{array}{r}
V_{t}^{m s}\left(\epsilon_{i}\right)=\epsilon_{i}-u_{d}+\beta \int_{\gamma}\left[\lambda V_{t+1}^{s s}+(1-\lambda)\left(V_{t+1}^{m s}\left(\epsilon_{i}\right)+\frac{M_{t+1}}{S_{t+1}} \theta(\right.\right. \\
\left.\left.\left.\frac{b_{t+1}}{B_{t+1}} \Pi_{t+1}^{b, m s}+\frac{b s_{t+1}}{B_{t+1}}\left(1-\frac{M_{t+1}}{S_{t+1}}+\frac{M_{t+1}}{S_{t+1}}\left(1-d_{t+1}^{s e l l}\right)\right) \Pi_{t+1}^{b s, m s}\right)\right)\right]
\end{array}
$$

In words, with probability $\lambda$ the dual position seller becomes mismatched and becomes a member of ss. With probability $(1-\lambda)$, the dual position seller stays matched and is on the market as a seller. The intuition for the remaining terms is as described above. As we did for $V^{m}$, we can express $V^{m s}$ as a component that depends on the match quality, $\epsilon_{i}$, and an additively separable component that does not: $\tilde{\epsilon}_{i}+U_{t+1}^{m s}$.

\subsubsection{Dual Position External Sellers}

The expected lifetime utility of being a dual position external seller is

$$
\begin{aligned}
& V_{t}^{s s}=u_{m m o}-u_{d}+\beta \int_{\gamma}\left(V_{t+1}^{s s}+\frac{M_{t+1}}{S_{t+1}}\left(2-\frac{M_{t+1}}{S_{t+1}}\right) \theta(\right. \\
& \left.\left.\frac{b_{t+1}}{B_{t+1}} \Pi_{t+1}^{b, s s}+\frac{b s_{t+1}}{B_{t+1}}\left(1-\frac{M_{t+1}}{S_{t+1}}+\frac{M_{t+1}}{S_{t+1}}\left(1-d_{t+1}^{s e l l}\right)\right) \Pi_{t+1}^{b s, s s}\right)\right)
\end{aligned}
$$

Note that the probability of a match is $\frac{M}{S}\left(2-\frac{M}{S}\right)$ because dual position external sellers have two homes to sell and so they have two opportunities to match with a buyer. 


\subsubsection{External Sellers}

The expected lifetime utility of being an external seller is

$$
V_{t}^{s}=u_{m m o}+\beta \int_{\gamma}\left(V_{t+1}^{s}+\frac{M_{t+1}}{S_{t+1}} \theta\left(\frac{b_{t+1}}{B_{t+1}} \Pi_{t+1}^{b, s}+\frac{b s_{t+1}}{B_{t+1}}\left(1-\frac{M_{t+1}}{S_{t+1}}+\frac{M_{t+1}}{S_{t+1}}\left(1-d_{t+1}^{s e l l}\right)\right) \Pi_{t+1}^{b s, s}\right)\right)
$$

\subsubsection{Buyer-Seller}

The expected lifetime utility of being a buyer-seller is

$$
\begin{aligned}
& V_{t}^{b s}=u_{m m}+\beta \int_{\gamma}\left[V_{t+1}^{b s}+\frac{M_{t+1}}{S_{t+1}}\left(1-\frac{M_{t+1}}{B_{t+1}}+\frac{M_{t+1}}{B_{t+1}} d_{t+1}^{\text {sell }}\right) \theta(\right. \\
& \left.\frac{b_{t+1}}{B_{t+1}} \Pi_{t+1}^{b, b s}+\frac{b s_{t+1}}{B_{t+1}}\left(1-\frac{M_{t+1}}{S_{t+1}}+\frac{M_{t+1}}{S_{t+1}}\left(1-d_{t+1}^{\text {sell }}\right)\right) \Pi_{t+1}^{b s, b s}\right)+ \\
& \frac{M_{t+1}}{B_{t+1}}\left(1-\frac{M_{t+1}}{S_{t+1}}+\frac{M_{t+1}}{S_{t+1}}\left(1-d_{t+1}^{\text {sell }}\right)\right)(1-\theta)\left(\frac{m s_{t+1}}{S_{t+1}} \Pi_{t+1}^{b s, m s}+\frac{s_{t+1}}{S_{t+1}} \Pi_{t+1}^{b s, s}+\right. \\
& \left.\left.\frac{b s_{t+1}}{S_{t+1}}\left(1-\frac{M_{t+1}}{B_{t+1}}+\frac{M_{t+1}}{B_{t+1}} d_{t+1}^{\text {sell }}\right) \Pi_{t+1}^{b s, b s}+\frac{2 s s_{t+1}}{S_{t+1}}\left(1-\frac{M_{t+1}}{2 S_{t+1}}\right) \Pi_{t+1}^{b s, s s}\right)\right]
\end{aligned}
$$

Note that the term multiplying $\theta$ reflects the case where the buyer-seller matches with a buyer and decides to pursue the match with a buyer, and the term multiplying $(1-\theta)$ reflects the case where the buyer-seller matches with a seller and decides to pursue the match with a seller.

\subsection{Market Equilibrium}

A policy rule is a function

$$
\delta_{i}\left(\Omega, \epsilon_{i}\right) \rightarrow A
$$

which maps the state variables and the outcome of the matching process, $\epsilon_{i}$, into an action A for player type $i=b, b s, s, m s, s s$. Note that $\epsilon$ can be the empty set if a match does not occur. If a match occurs, the action space is either to transact or not transact. Else, the only action is to not transact. Note that members of $b s$ have an additional policy rule, $\delta_{b s}^{\text {sell }}(\Omega) \rightarrow A^{\prime}$, where the action space is to pursue the match as a buyer or as a seller in the event that $b s$ matches with both a buyer and a seller. 
A belief is a function

$$
\sigma_{i j}(\Omega) \rightarrow \operatorname{Pr}\left(\delta_{i}=j \mid \Omega, i\right) .
$$

which maps each state into a probability distribution over the potential actions $j$ for a type $i$ player. A player's beliefs do not depend on $\epsilon_{i}$ because each player is of inconsequential size relative to the entire economy.

Definition 1 A Markov perfect equilibrium is a collection of policy rules, $\delta_{i} \forall i$, and a set of beliefs, $\sigma_{i j}(\Omega) \forall i, j, \Omega$, such that

1. The policy rules are optimal.

2. Agents have the correct beliefs about other players' policy rules.

We focus on a symmetric equilibrium in which all agents have identical beliefs. ${ }^{19}$

\subsection{Equilibrium Price}

There are eight possible transaction types in the model economy (four types of sellers by two types of buyers). The solution to the complete information Nash bargaining problem for each of the transaction types gives the following prices:

1. $b$ buys from $b s$

$$
\text { - } p^{*}(b, b s)=\theta\left(U^{m}-V^{b}+\tilde{\epsilon}_{b, b s}^{*}\right)-(1-\theta)\left(V^{b}-V^{b s}\right)
$$

2. $b$ buys from $s$

$$
\text { - } p^{*}(b, s)=\theta\left(U^{m}-V^{b}+\tilde{\epsilon}_{b, s}^{*}\right)-(1-\theta)\left(\frac{u_{O}}{1-\beta}-V^{s}\right)
$$

3. $b$ buys from $m s$

\footnotetext{
${ }^{19}$ In the classic dynamic search models, increasing returns to scale for the matching technology is a necessary condition for multiple equilibria (Pissarides [2000]). While we do not have a formal proof of uniqueness for our particular model, we note that 1) our matching function is CRS and 2) for the parameter vector that best fits the data, we searched numerically for other equilibria, but always converged to a unique equilibrium regardless of the initial conditions.
} 
- $p^{*}(b, m s)=\theta\left(U^{m}-V^{b}+\tilde{\epsilon}_{b, m s}^{*}\right)-(1-\theta)\left(V^{m}-V^{m s}\right)$

4. $b$ buys from $s s$

- $p^{*}(b, s s)=\theta\left(U^{m}-V^{b}+\tilde{\epsilon}_{b, s s}^{*}\right)-(1-\theta)\left(V^{s}-V^{s s}\right)$

5. bs buys from $b s$

- $p^{*}(b s, b s)=\theta\left(U^{m s}-V^{b s}+\tilde{\epsilon}_{b s, b s}^{*}\right)-(1-\theta)\left(V^{b}-V^{b s}\right)$

6. bs buys from $s$

- $p^{*}(b s, s)=\theta\left(U^{m s}-V^{b s}+\tilde{\epsilon}_{b s, s}^{*}\right)-(1-\theta)\left(\frac{u_{O}}{1-\beta}-V^{s}\right)$

7. bs buys from $m s$

- $p^{*}(b s, m s)=\theta\left(U^{m s}-V^{b s}+\tilde{\epsilon}_{b s, m s}^{*}\right)-(1-\theta)\left(V^{m}-V^{m s}\right)$

8. bs buys from ss

- $p^{*}(b s, s s)=\theta\left(U^{m s}-V^{b s}+\tilde{\epsilon}_{b s, s s}^{*}\right)-(1-\theta)\left(V^{s}-V^{s s}\right)$

where $\tilde{\epsilon}_{i, j}^{*}$ is random variable truncated from below by the value that sets the total surplus associated with the transaction equal to zero. The total surplus associated with each transaction is described in the Appendix. For each transaction type, the price is equal to the buyer's surplus, weighted by the seller's bargaining power, minus the seller's surplus, weighted by the buyer's bargaining power. The Appendix outlines the equations for the equilibrium transaction volumes and the laws of motion.

\section{Basic Results and Mechanisms}

\subsection{Price Dispersion}

The price equations in Section 3.8 show how the search structure of the model and the very limited heterogeneity we impose naturally deliver equilibrium price dispersion, which is a well-established property of housing markets. One source of heterogeneity that generates 
dispersion is the idiosyncratic match quality, $\epsilon$. As shown in Section 3.8, the match quality enters directly into the price equations and so prices will vary across identical homes depending on how well matched the buyer is to the particular home.

The model can also generate price dispersion precisely from the type of heterogeneity that was shown to generate dispersion in the data in Section 2. More specifically, the model generates price differences between external and internal sellers, and price differences between internal movers who buy versus sell first.

When those sellers leaving the city have higher effective holding costs than those moving internally - i.e., when $u_{m m}>u_{m m o}$ - prices will tend to be lower for external versus internal sales. The reason is that higher holding costs increase the surplus that an external seller receives from a transaction relative to an internal seller. This increased surplus leads to lower realized transaction prices through two channels: (i) lowering the price that the seller receives in Nash bargaining and (ii) reducing the minimum match quality draw, $\tilde{\epsilon}^{*}$, needed to generate a positive total surplus.

Likewise, a higher effective cost of holding multiple properties - i.e., a relatively high value for $u_{d}$ - works in an exactly analogous way to lower the selling price accepted by internal movers who buy first relative to internal movers who sell first. The reason is that a higher value of $u_{d}$ increases the surplus for those sellers who are currently holding two properties, which lowers the price that the seller receives because the two effects on price (directly through Nash bargaining and indirectly through the reservation match quality) again work in the same direction to lower average prices.

Interestingly, the net effect of high $u_{d}$ on the price paid by internal movers who buy first relative to internal movers who sell first is less clear because these two effects now work in opposite directions. When buying-before-selling, the buyer's surplus from buying is low due to the high holding costs associated with owning two homes, which tends to lower the price. But it also raises the minimum match quality draw, $\tilde{\epsilon}^{*}$, needed to generate positive total surplus, which works to raise the average price. 


\subsection{Market Tightness and "Buyer's" and "Seller's" Markets}

In the model, the stochastic inflow of new buyers generates volatility over time in market tightness, or the ratio of buyers to sellers, $B / S .^{20}$ This causes fluctuations in the probability of a match $(M(B, S) / B$ for buyers and $M(B, S) / S$ for sellers), which enters directly into the value functions associated with each type of buyer and seller, as shown above.

Our model provides a natural economic analogue to the popular terms "buyer's" and "seller's" markets based on the value of being a buyer or seller in the market at different levels of market tightness. For example, a sequence of high realizations of the inflow process creates a "seller's" market by increasing market tightness and therefore the value function associated with being a seller. This can be seen from the value functions presented in Section 3. A large inflow increases the size of the buyer pool, $B$, which increases the number of matches, $M(B, S)$ for a fixed stock of sellers, $S$. Given that sellers in the model are always flowing into the market at an exogenous rate, the probability that a seller gets matched with a buyer in any period $(M(B, S) / S)$ is also generally higher. This increases the value function associated with being a seller because it allows for more sampling of idiosyncratic match quality draws, $\epsilon$, in a given amount of time. Therefore, the seller's surplus associated with any transaction is lower because the outside option of not selling the house and staying on the market is higher. Under Nash bargaining, lower seller surplus increases the price, as shown in the equilibrium price equations in Section 3.8. Conversely, a sequence of low realizations of the inflow process lowers market tightness, creating a "buyers" market where the arrival rate of buyers is low and consequently, prices are lower. Mechanically, this is how price fluctuations are generated in the economy.

\subsection{The Role of Buyer-Sellers}

A key focus of this paper is to determine whether the endogenous response of buyer-sellers (i.e. members of the $b s$ pool) amplifies or dampens "buyer's" and "seller's" markets caused by the exogenous inflow fluctuations. The model presented above actually allows for both

\footnotetext{
${ }^{20}$ Indeed, if the variance of the inflow process were set to zero, the equilibrium would be characterized by a steady state with zero equilibrium volatility in prices and volume.
} 
possibilities and the answer depends on parameter values, especially $u_{d}$. To understand how, suppose $u_{d}$ is high so that the flow utility associated with being a dual position seller $(m s)$ is low. When inflow is low and thus the probability of matching with a buyer is low, sellers who buy before selling will expect to accrue the low flow utility associated with being a dual position seller for a relatively long period of time, and so $V^{m s}$ becomes low relative to $V^{b s}$. Conversely, when inflow is high and thus the probability of matching with a buyer is high, $V^{m s}$ is not as sensitive to $u_{d}$ because the expected number of periods of having to accrue $u_{d}$ is smaller. As a result, it will take a larger value of $\epsilon_{i}$ to push a buyer-seller to buy before selling in a "buyer's" market relative to a "seller's" market. In this way, demand from internal movers (i.e. buyer-sellers) can endogenously become correlated with external demand.

On the other hand, if $u_{d}$ is not that high, then internal demand can actually work to smooth fluctuations in external demand. To see how, consider the extreme case where $u_{d}$ is sufficiently low such that all internal movers want to buy before selling. In this case, even when external demand is low, there is still steady demand from buyer-sellers who become mismatched and enter the market at a constant, exogenous rate and are immediately ready to buy. This steady demand by buyer-sellers helps to dampen the fluctuations due to the fundamental movements in external demand.

\subsection{Internal Movement}

Whether internal transaction volume is more volatile and pro-cyclical than external transaction volume is closely connected to the endogenous response of buyer-sellers discussed above. The model can generate more volatility in internal transaction volume when $u_{d}$ is high, and $u_{m m}$ is high relative to $u_{m m o}$. In this case, internal movers will tend to sell when inflow is high (and prices are generally high) for the reasons discussed above. External movers will generally sell much sooner upon mismatch - and therefore, their transaction volume will be steadier - because their effective holding cost of having the house unsold is higher (i.e. low $u_{m m o}$ relative to $u_{m m}$ lowers $V^{s}$ relative to $\left.V^{b s}\right)$. 


\section{Estimation}

\subsection{Parametric Assumptions}

In taking the model to the data, we make functional form assumptions on the matching technology, the inflow process, and the idiosyncratic match quality. Following Pissarides (2000), we assume the Cobb-Douglass form for the matching technology:

$$
M(B, S)=A B^{\eta} S^{1-\eta}
$$

and so the probability of a match will depend directly on the market tightness, or the ratio of buyers to sellers.

We assume that the inflow process follows a normal distribution

$$
\gamma_{t} \sim N\left(\mu_{\gamma}, \sigma_{\gamma}^{2}\right)
$$

and that the mean and variance of the inflow distribution are time-invariant. ${ }^{21}$

We assume that the match quality $\epsilon$ is normally distributed:

$$
\epsilon \sim N\left(u_{m}, \sigma^{2}\right)
$$

The advantage of this normality assumption for computation is that all of the conditional expectations in the value functions can be expressed as simple functions of normal pdfs and cdfs using properties of the truncated normal distribution. Further details are provided in the Appendix.

The parameter values of the model are determined in two steps. In a first step, we make several exogenous assumptions and calibrate any parameters for which there is a one-to-one mapping between the parameter value and some feature of the data. Then, the remaining parameter values are estimated through simulated method of moments. Table 4 summarizes the parameters of the model.

\footnotetext{
${ }^{21}$ In practice, we truncate the inflow distribution from below at zero so that the probability of a negative draw equals zero. For our choice of $\mu_{\gamma}, \sigma_{\gamma}^{2}$, the probability of a negative inflow draw is tiny and so truncating the distribution has little effect on our results.
} 


\subsubsection{Parameters Calibrated a Priori}

We assume that each period in the model is equal to one month. We set the monthly discount factor, $\beta$, so that the annual discount rate is 0.95 . We assume symmetric bargaining power $(\theta=0.5)$. We set the mismatch rate, $\lambda$, so that mismatch occurs about once every 10 years, which is roughly consistent with the average housing tenure in the American Housing Survey. We assume that the flow utility associated with exiting the housing market, $u_{O}$, equals $u_{m}$. We calibrate the share of newly mismatched owners that also become mismatched with the city to be $(1-\pi)=1 / 3$ to match the average internal move share calculated from the data in Table 1 . We calibrate the mean of the inflow process, $\mu_{\gamma}$, so that average inflows and outflows of agents in the economy are balanced. At our choice of $\lambda$ and $\mu_{\gamma}$, the annual average transaction volume as a share of the total housing stock predicted by the model is equal to .08, the average value in the data for the U.S. ${ }^{22}$ We set the exponent of the matching function, $\eta$, equal to 0.84 to match the contact elasticity for sellers with respect to the buyer-to-seller ratio estimated in Genesove and Han [2012] based on the National Association of Realtors survey. We set $A=1 / 2$, which in our simulations generally leads to match probabilities that lie in the unit interval, although for estimation we also mechanically bound the probability of a match at one.

\subsubsection{Parameters Estimated by Simulated Method of Moments}

The remaining unknown parameters are the flow utility parameters $u_{m}, \sigma^{2}, u_{m m}, u_{m m o}, u_{d}$, $u_{b}$; and the variance of the inflow process, $\sigma_{\gamma}^{2}$. We normalize $u_{b}=0$ and $u_{m}=1$. We choose the unknown parameters so as to best match the following moments:

- The mean and coefficient of variation of median time on market, and the correlation of median time on market with real price changes.

- The coefficient of variation of sales volume, and the correlation of sales volume with real price changes.

- The coefficient of variation of real price.

\footnotetext{
${ }^{22}$ Source: a HUD report titled "U.S. Housing Market Conditions." We use a national figure because the figure for Los Angeles is unavailable.
} 
- The mean within-period coefficient of variation of price (i.e. equilibrium price dispersion). ${ }^{23}$

- The mean of the fraction of internal movers who buy first, and the correlation of this fraction with real price changes.

- The correlation of the internal move share with real price changes.

- The average price received by external sellers relative to the average price received by internal sellers.

All of these means, variances, and correlations are taken over the time series. To be consistent with the data, each variable is aggregated to its annual level first. All changes are 1 year changes. We set the weighting matrix so that each category of moments, which are distinguished by the bullet points above, are given equal weight in estimation, and each moment within a category is given a weight proportional to the number of moments in the category. ${ }^{24}$

Simulating the model involves solving for each of the value functions defined above. We do this through value function iteration combined with linear (in parameters) interpolation, which is necessary because the state space is continuous. Since the integrals are one-dimensional given our assumption on the inflow process, we use quadrature to approximate them. Note that once we have simulated the value functions, no additional simulation is required to compute average prices or transaction volume given that the idiosyncratic component of price and total surplus (i.e. the component that is not deterministic given the state $\Omega_{t}$ ) is additively separable, as shown in Section 3.8.

\footnotetext{
${ }^{23}$ To calculate within-period price dispersion in the data, we measure the standard deviation of the price residual after partialing out time-invariant housing quality and year-by-zip code fixed effects using a repeat sales specification.

${ }^{24}$ For example, the correlation of median time on market with real price changes is given a weight equal to $1 / 3$.
} 


\section{Model Fit and Discussion}

The parameter estimates and the simulated moments we target are reported in Tables 3 and 4. ${ }^{25}$ The parameter values are sensible: (i) a matched homeowner with a match quality one standard deviation above the mean receives a flow utility that is 8 percent higher than a homeowner with the mean match quality, (ii) a mismatched homeowner receives about a 15 percent lower flow utility than a matched homeowner with a match quality one standard deviation above the mean (iii) the mean flow utility of holding two positions, $u_{m}-u_{d}$, is significantly lower than that of being either matched well or mismatched with a single home (iv) a homeowner mismatched with the city receives a 40 percent lower flow utility that a mismatched homeowner who is still matched with the city $(\mathrm{v})$ the flow utility of owning zero homes is less than the flow utility of being either matched well or mismatched with a single home, but it is not so low so as to substantially discourage internal movers from selling before buying. ${ }^{26}$

Qualitatively the model fit is also good. The estimated model generates a significant amount of volatility while fitting the sign of the correlations between price, volume, time on market, the internal move share, and buy-before-sells observed in the data. The fit on the moments using time-on-market are the poorest; however, a few studies have noted that TOM data as reported by realtors is noisy. ${ }^{27}$ Although the estimated model can generate a level of price volatility comparable to what is observed in the data, similar to other studies, we do not generate enough volume volatility over the cycle.

The model performs well on a number of other moments that we do not specifically target in estimation. The estimated model predicts a correlation between end of year unsold

\footnotetext{
${ }^{25}$ The weighting matrix is calculated using the 2-step procedure described in Lee and Wolpin [2010]. The variance-covariance matrix of the parameter estimates is given by $\left(G^{\prime} W G\right)^{-1}$, where $G$ is the matrix of derivatives of the moments with respect to the parameters and $W$ is the weighting matrix.

${ }^{26}$ For costs of owning zero homes sufficiently low, agents may actually prefer to buy before selling, particularly in hot markets when it can take a while to find a home as a buyer.

${ }^{27}$ See, for example, the discussion in Levitt and Syverson [2008]. This has led to a wide range of calibrations in the literature. For example, Caplin and Leahy [2011] use an average TOM of 3 months; Burnside et al.
} [2011] use 7.5 months. 
inventory (i.e. mismatch) and real price of -0.92 . In the data, the correlation is $-0.87 .^{28}$ The negative correlation between mismatch and price can be seen in Figure 7, which plots one twenty year simulation (the length of our sample period) from the estimated model. During price busts, the pool of mismatched homeowners endogenously builds despite the exogenous, time-invariant rate of mismatch. This occurs because 1) the probability of matching with a buyer is relatively low (i.e. the price decline is driven by low inflow into the buyer pool) and 2) sellers would rather wait until inflow and prices recover to sell. As we will show below, the high effective holding cost of holding two positions is key for point 2). When inflow into the market strengthens, mismatch is released as the probability of matching with a buyer and prices both increase. Note that in Figure 7, the level of internal mismatch (i.e. members of $b s$ and $m s$ ) is comparable to the level of external mismatch (i.e. members of $s$ and $s s$ ) despite the fact that the transition rate into internal mismatch is only one half the transition rate into external mismatch. The reason is that holding costs for external sellers are estimated to be higher than those for internal sellers and so it is more costly for external sellers to wait to sell until prices recover. The steadier outflow of external movers combined with the endogenous build-up and release of internal movements results in the pro-cyclicality of the internal move share.

As in the data presented in Table 2, the model predicts that internal movers who buybefore-selling sell for a lower average price relative to internal movers who sell first. However, the model over predicts the magnitude of the discount (the model generates a 13 percent discount). The model also successfully predicts that buying-before-selling has a larger impact on the selling price accepted by internal movers compared to the price paid. But here again, the model over predicts the magnitude of the difference (the discount on price paid by internal movers predicted by the model is 7 percent).

\footnotetext{
${ }^{28}$ This correlation is for the aggregate U.S. housing market. The data source is the American Housing Survey and the National Association of Realtors. Inventory is normalized by the owner-occupied housing stock.
} 


\section{Sources of Volatility and the Pro-Cyclicality of In- ternal Movement}

In this section, we quantify the contribution of the two key sources of friction in the model 1) basic search/matching frictions, 2) frictions due to the joint buying and selling decisions of internal movers - to market volatility and seek to understand how the effect of the joint buyer-seller frictions vary with the key parameters of the model. We do so through a series of counterfactual simulations. ${ }^{29}$

\subsection{Joint Buyer-Seller Versus Search Frictions}

To isolate the role of joint buyer-seller frictions, we compare the baseline model to a simulation in which there is no joint buyer-seller problem. Mechanically, we do this by assuming that there is no internal movement so that upon being mismatched, all sellers receive the time-invariant and market conditions-invariant lifetime utility $V^{O}=\frac{u_{O}}{(1-\beta)}$ upon selling and there is no re-entry into the buyer pool. As in the baseline model, we continue to assume there are two types of mismatch shocks each providing a different level of mismatch flow utility. So in this model, there are four types of agents: buyers, matched owners, mismatched owners receiving flow utility $u_{m m}$, and mismatched owners receiving flow utility $u_{m m o}$. We also increase the mean of the inflow process so that inflow into the buyer pool is comparable to the baseline model.

Table 5 shows volatility (defined as the coefficient of variation) in prices, transaction volume, and time on market for this counterfactual model relative to the baseline model. The counterfactual model without joint buyer-seller frictions generates only 35 percent of the price volatility, 90 percent of the volume volatility, and 80 percent of the time on market volatility as in the baseline model. This implies that, at the parameter values that best fit the data, the joint buyer-seller problem increases the volatility of transaction volumes and time on market by about 10-20 percent and, more importantly, more than doubles the price volatility. As we discuss below, such an increase in price volatility is likely to have a number

\footnotetext{
${ }^{29}$ In each simulation, the seed for the inflow process is set to be the same so that differences in the simulated dynamics are not the result of simulation noise.
} 
of important welfare consequences for home owners and the economy more generally.

\subsection{The Cost of Holding Two Homes and Joint Buyer-Seller Fric- tions}

To better understand how the effective cost of holding two homes gives rise to these important frictions associated with the joint buyer-seller problem, we conduct another counterfactual simulation that lowers the cost of holding two homes - $u_{d}$ - in the model. In practice, the owner of two houses might be able to capture more of the consumption flow of a vacant home if short-term rental frictions were not as severe. We make these changes relative to the baseline model, so that the comparison of the results to the baseline model characterizes how the cost of holding two positions affects equilibrium dynamics in the model.

Table 5 shows volatility for values of $u_{d}$ equal to one-half the baseline estimate, $u_{d}$ equal to zero, and $u_{d}$ equal to $-0.5 * u_{m m}$. Market volatility declines monotonically with the effective cost of holding two positions simultaneously and, interestingly, when the cost of holding two positions is sufficiently low (e.g., for the simulation where $u_{d}=-0.5 * u_{m m}$ ) volume, time on market, and price volatility fall below the levels associated with the first counterfactual simulation, which eliminated the joint buyer-seller frictions altogether. In this case, the presence of internal movers within the metropolitan area actually works to smooth the fluctuations that come from external demand! For example, when there is a negative shock to the pool of external buyers, demand from internal movers compensates because buying conditions are favorable; internal movers buy their next home now and worry about selling the home with which they are mismatched later.

These results make it clear that the general effect of having agents operating simultaneously on both sides of a market is ambiguous and depends directly on whether the costs of holding two properties are such that increases in external demand lead to (i) increases in internal demand due to a thick market effect or (ii) decreases in internal demand due to a competitive or smoothing effect. Thus, while the results of this paper clearly establish that the dual buyer-seller problem amplifies price volatility in housing markets, the presence of these agents might help to smooth price fluctuations in other markets in which the costs (or 
lack of utility) associated with holding two units simultaneously are not as high.

\subsection{Endogenous Variation in Attractiveness of Holding Two Po- sitions}

The results presented in Table 5 show that a time invariant cost of holding two positions significantly amplifies fundamental volatility. The reason is that in the presence of search frictions, the total attractiveness of taking on two positions depends not only on the perperiod cost of holding two positions but also on the expected length of time that one expects to incur the cost. This length of time is shorter during booms and longer during busts, and so the attractiveness of holding two positions is pro-cyclical. Through this mechanism, internal demand becomes positively correlated with external demand, causing prices to rise more during booms and fall more during busts than they otherwise would in a market where agents' buying and selling decisions are not complementary.

Figure 8 compares the price dynamics for a simulation of the baseline model, the model without internal movement, and the model in which $u_{d}$ is counterfactually set to equal $-0.5 * u_{m m}$. The amplification of house price cycles due to the joint buyer-seller problem when the costs of holding two positions are high is immediately obvious in the figure.

As discussed above, the pro-cyclicality of internal movements comes from the endogenous build up and release of internal movement over the cycle, combined with the steadier outflow of sellers who are mismatched with the city. Since the cost of holding two positions exacerbates the build up and release of internal movement, the pro-cyclicality of internal movement is strongest in the baseline model. Figure 9 illustrates this point. We plot mismatch in the baseline model and mismatch in the model where $u_{d}=-0.5 * u_{m m}$ for the same 20 year period shown in Figure 8. The cost of holding two positions drives the build-up and release of mismatch over the cycle, which is much more prevalent in the high holding costs baseline model. The build-up and release of mismatch generates the pro-cyclicality of internal movement. As a result, the correlation between price and both internal and total transaction volume is greatest in the baseline model. 


\section{Policy and Welfare}

Our results so far suggest that much of the aggregate housing market volatility is related to the volatility in the internal mover share. In this section, we consider, in the context of our estimated model, whether a revenue neutral policy intervention can reduce volatility in internal movement relative to external movement, thereby decreasing aggregate volatility and potentially increasing welfare.

We consider a policy that subsidizes both the per-period utility of holding two homes $\left(u_{d}\right)$ and the per-period utility of being mismatched with the city $\left(u_{m m o}\right)$. A subsidy to $u_{d}$ makes the moving decisions of buyer-sellers less sensitive to the cycle and a subsidy to $u_{m m o}$ (which brings $u_{m m o}$ closer to $u_{m m}$ ) better aligns the costs of staying on the market for internal and external sellers, which should reduce volatility in internal movement relative to external movement. To keep the policy intervention revenue neutral, we also impose a tax on each transaction. We choose the value of the two subsidies and the transaction tax optimally to maximize social welfare subject to revenue neutrality. We define the social welfare function in the Appendix. We solve this problem numerically using a constrained optimization routine.

Table 6 shows that the policy scheme reduces volatility in prices, volume, and time on market by a comparable amount as the counterfactual simulations presented in Table 5, and increases welfare per transaction by 4200 dollars. The optimal transactions tax is equal to 2.24 (3.8 percent of the average price) and the subsidies are such that $u_{d}$ and $u_{m m o}$ effectively become .06 and 1.23, respectively.. The policy intervention affects welfare by effectively increasing the reservation match quality for buyers and sellers - especially for members of $m s$ and $s$ who are most directly influenced by the subsidy. This is precisely what the social planner would like to do in a classic search model with idiosyncratic match quality. In such a framework, the private benefit of searching for a higher match quality draw is generally smaller than the social benefit because each agent only receives a share of the gains from a higher match quality according to his bargaining weight. ${ }^{30}$ By effectively

\footnotetext{
${ }^{30}$ Additional details are provided in Pissarides [2000]. One difference between our search model and the canonical labor search models is that in our model, entry of agents into the pool of active buyers and sellers is exogenous. Thus, we do not get any inefficiency from an entry margin. In the Diamond-Mortenson-Pissarides
} 
lowering the cost of waiting for a higher match quality draw, our policy more closely aligns private and social search incentives, and thus increases welfare.

It is worth emphasizing that our model likely substantially understates the welfare benefits of the policy intervention because it does not fully capture the benefits of reduced price volatility for market participants (as they are assumed to be risk neutral) and for the broader economy. ${ }^{31}$ While real world analogues that replicate the kinds of holding subsidies we consider here are not obvious, these results suggest that a lack of liquidity for high holding cost sellers is an important source of social welfare loss, and that sizable welfare gains and decreases in housing price volatility could be achieved through mechanisms that increase liquidity in the market.

\section{Conclusion}

Our paper is motivated by new empirical evidence that we document on internal movement over the metropolitan-area housing-market cycle. We find that a significant share of overall transaction volume consists of households buying and selling homes at about the same time. Such internal movement is highly volatile and drives the pro-cyclicality of overall transaction volume. We show that these and other well-established stylized facts about housing market cycles can be matched very well with only a modest extension to classical search theory. In particular, we extend the Diamond-Mortensen-Pissarides search model only to (i) endogenize the decisions of internal movers to buy or sell first and (ii) account for the fact that it is costly for households to own two homes simultaneously, even for a short amount of time. With this framework, we show that the joint buyer-seller problem in particular amplifies fundamental volatility and gives rise to significant welfare loss.

Perhaps an optimistic message from our paper is that a significant portion of housing framework, welfare is affected by inefficient entry (i.e. too much or too little job creation) depending on the Hosios condition.

${ }^{31}$ See Chan [1997], Ferreira et al. [2010], Campbell et al. [2011], Anenberg and Kung [2014], Melzer [2012], Case et al. [2005], Mian and Sufi [2011] for evidence and a discussion of the social costs of house price volatility, including foreclosure externalities, restricted mobility (although the empirical evidence here is mixed), debt overhang, and consumption volatility. 
market volatility is not an unavoidable consequence of the existing technology for buying and selling homes. Our results show that a natural role for homeowners moving with a metropolitan area is to smooth shocks to external demand and dampen aggregate volatility, if only they could more easily buy and sell homes in a thin market. Indirect policies or technologies that could alleviate this constraint for internal movers and thus decrease equilibrium volatility could include 1) making tax and legal policies more accommodative for flippers who act to provide liquidity to high holding cost sellers, 2) using the internet to facilitate a market for short term rental ${ }^{32}$, and 3) easing financing constraints that may serve to effectively increase the costs of holding two homes (e.g. make bridge loans more accessible).

\footnotetext{
${ }^{32}$ Examples of such platforms include www.airbnb.com and www.craigslist.org.
} 


\section{References}

James Albrecht, Axel Anderson, Eric Smith, and Susan Vroman. Opportunistic matching in the housing market. International Economic Review, 48(2):641-664, 2007.

Elliot Anenberg. Loss aversion, equity constraints and seller behavior in the real estate market. Regional Science and Urban Economics, 41(1):67 - 76, 2011.

Elliot Anenberg and Edward Kung. Estimates of the size and source of price declines due to nearby foreclosures. American Economic Review, 104(8):2527-51, 2014.

Patrick Bayer, Christopher Geissler, and James W. Roberts. Speculators and middlemen: The role of flippers in the housing market. Working Paper 16784, National Bureau of Economic Research, February 2011.

Craig Burnside, Martin Eichenbaum, and Sergio Rebelo. Understanding booms and busts in housing markets. Working Paper 16734, National Bureau of Economic Research, January 2011.

John Campbell, Stefano Giglio, and Parag Pathak. Forced sales and house prices. American Economic Review, 101(5):2108-31, 2011.

Andrew Caplin and John Leahy. Trading frictions and house price dynamics. Journal of Money, Credit and Banking, 43:283-303, 2011.

Paul E. Carrillo. An empirical stationary equilibrium search model of the housing market*. International Economic Review, 53(1):203-234, 2012.

Karl E. Case and Robert J. Shiller. The efficiency of the market for single-family homes. The American Economic Review, 79(1):125-137, 1989.

Karl E Case, John M Quigley, and Robert J Shiller. Comparing wealth effects: the stock market versus the housing market. Advances in macroeconomics, 5(1), 2005.

Sewin Chan. Spatial lock-in: Do falling house prices constrain residential mobility? Journal of Urban Economics, 49(3):567-568, 1997. 
N. Edward Coulson and Paul L.E. Grieco. Mobility and mortgages: Evidence from the psid. Regional Science and Urban Economics, 43(1):1 - 7, 2013.

Antonia Diaz and Belen Jerez. House prices, sales, and time on the market : a searchtheoretic framework. International Economic Review, 54(3):837-872, 2013.

Gary Engelhardt. Nominal loss aversion, housing equity constraints, and household mobility: evidence from the united states. Journal of Urban Economics, 53(1):171-195, 2003.

Fernando Ferreira, Joseph Gyourko, and Joseph Tracy. Housing busts and household mobility. Journal of Urban Economics, 68(1):34 - 45, 2010.

David Genesove and Lu Han. Search and matching in the housing market. Journal of Urban Economics, 2012.

David Genesove and Christopher Mayer. Loss aversion and seller behavior: Evidence from the housing market. The Quarterly Journal of Economics, 116(4):1233-1260, 2001.

Edward L. Glaeser, Joseph Gyourko, and Raven Saks. Why have housing prices gone up? The American Economic Review, 95(2):pp. 323-328, 2005.

Allen Head, Huw Lloyd-Ellis, and Hongfei Sun. Search, liquidity, and the dynamics of house prices and construction. The American Economic Review, 104(4):1172-1210, 2014.

John Krainer. A theory of liquidity in residential real estate markets. Journal of Urban Economics, 49(1):32 - 53, 2001.

Donghoon Lee and Wilbert Van der Klaauw. An introduction to the frbny consumer credit panel. Working Paper 479, FRB of New York Staff, November 2010.

Donghoon Lee and Kenneth I. Wolpin. Accounting for wage and employment changes in the us from 1968-2000: A dynamic model of labor market equilibrium. Journal of Econometrics, 156(1):68 - 85, 2010.

Steven D. Levitt and Chad Syverson. Market distortions when agents are better informed: The value of information in real estate transactions. Review of Economics and Statistics, 90(4):599-611, 2008. 
Brian Melzer. Mortgage debt overhang: Reduced investment by homeowners with negative equity. Working paper, August 2012.

Atif Mian and Amir Sufi. House prices, home equity-based borrowing, and the us household leverage crisis. American Economic Review, 101(5):2132-56, 2011.

Raven Molloy and Hui Shan. The postforeclosure experience of us households. Real Estate Economics, 2012.

Dale T. Mortensen and Christopher A. Pissarides. Job creation and job destruction in the theory of unemployment. The Review of Economic Studies, 61(3):397-415, 1994.

L. Rachel Ngai and Silvana Tenreyro. Hot and cold seasons in the housing market. American Economic Review, 104(12):3991-4026, 2014.

Robert Novy-Marx. Hot and cold markets. Real Estate Economics, 37(1):1-22, 2009.

Francois Ortalo-Magne and Sven Rady. Housing market dynamics: On the contribution of income shocks and credit constraints. Review of Economic Studies, 73(2):459-485, 2006.

Monika Piazzesi and Martin Schneider. Momentum traders in the housing market: Survey evidence and a search model. American Economic Review Papers and Proceedings, 99(2): 406-411, 2009.

Christopher Pissarides. Equilibrium unemployment theory. MIT Press, 2000.

John M. Quigley and Steven Raphael. Regulation and the high cost of housing in california. The American Economic Review, 95(2):pp. 323-328, 2005.

Jean-Marc Robin. On the dynamics of unemployment and wage distributions. Econometrica, 79(5):1327-1355, 2011.

Sam Schulhofer-Wohl. Negative equity does not reduce homeowners' mobility. Technical report, National Bureau of Economic Research, 2011.

Robert J. Shiller. Arithmetic repeat sales price estimators. Journal of Housing Economics, 1(1):110-126, 1991. 
Robert Shimer. The cyclical behavior of equilibrium unemployment and vacancies. The American Economic Review, 95(1):pp. 25-49, 2005.

Jeremy C. Stein. Prices and trading volume in the housing market: A model with downpayment effects. The Quarterly Journal of Economics, 110(2):379-406, 1995.

William C. Wheaton. Vacancy, search, and prices in a housing market matching model. Journal of Political Economy, 98(6):pp. 1270-1292, 1990.

\section{A Robustness of Stylized Facts on Internal Movement}

\section{A.1 Equifax Data}

This section describes how we use the FRBNY/Equifax Consumer Credit Panel to document internal movement. The panel comprises a nationally representative 5 percent random sample of US individuals with credit files. A detailed overview of the data can be found in Lee and Van der Klaauw [2010]. We observe credit information for each individual at a quarterly frequency. We classify an individual as having purchased a home in quarter $t$ (i.e. the denominator of the internal mover share) if the following conditions are satisfied: the mailing address reported to Equifax for quarter $t$ is different from the one reported in quarter $t-1$, a new first mortgage was opened in quarter $t$, the individual has at most one first mortgage open in quarters $t$ and $t-1 .^{33}$ Since some individuals temporarily have two first mortgages open (perhaps because they bought before selling), we also classify an individually as having purchased a new house if the conditions specified hold for quarters $t-2, t-3$, or $t-4$. Internal movers (i.e. the numerator of the internal mover share) are the subset of these movers where 1) a first mortgage existed in quarter $t-1$ that is not the same as the first mortgage in quarter $t$ and 2) the MSA in quarter $t$ is the same as the

\footnotetext{
${ }^{33}$ In period $t-1$, we allow the individual to have two first mortgages if the smaller is less than half the size of the larger mortgage to accommodate junior liens. This restriction is borrowed from Molloy and Shan [2012].
} 
MSA in quarter $t-1 .{ }^{34}$ For studying internal movement, an advantage of Equifax relative to Dataquick is that we have household identifiers so we do not need to match names. A disadvantage is that we rely on mortgage information to identify home purchases, so, for example, purchases where the buyer pays in cash are dropped from our analysis.

Appendix Figure 1 plots the internal mover share by year for MSAs in California, averaged across MSAs. We smooth through the year 2003 because there is an uptick in internal movement (not just in California but in all states) due to a change in Equifax's methodology of determining someone's address. The level of the internal mover share is similar to the level of the internal mover share calculated from the Dataquick data specifically for Los Angeles. The internal mover share is also pro-cyclical for MSAs in California. Interestingly, the internal mover share peaks just before the house price index, which we also find to be the case in Dataquick (see Figure 1). Since the Equifax data is nationally representative, we can also investigate across MSA differences in the dynamics of the internal mover share. The states in the left panel of Appendix Figure 1 had large price run-ups in the early 2000's, followed by large house price declines starting in the middle of the decade. The states in the right panel had more subdued house price dynamics according to CoreLogic. The evidence strongly suggests that the dynamics of internal movement are correlated with the house price cycle.

We also examine whether our finding in Dataquick that internal movers tend to sell before buying holds up in the Equifax data. In the Equifax data, we classify an internal mover as buying-before-selling if the mover temporarily has two first mortgages open. For MSAs in California, 30 percent of internal movers buy before sell on average, which is identical to the number we arrive at with Dataquick. For the country as a whole, the share is 25 percent.

\section{A.2 American Housing Survey}

We use the American Housing Survey data for Los Angeles to calculate the share of owneroccupied housing units with recent movers where the previous unit of the recent mover was also owner-occupied (Source: Table 3-10). This should overstate the internal mover share

\footnotetext{
${ }^{34}$ The mailing address in Equifax is a unique identifier, but is scrambled to preserve the anonymity of individuals. We do observe the unscrambled county and state, which we use to determine the MSA.
} 
as we define it because a move between two owner occupied units from one MSA to another would be included in the numerator. The survey is only conducted every 5 years or so, but the average share in the six most recent surveys is 40 percent, consistent with our finding that most housing transactions are external. The share is the highest in 1989 (during a house price boom) and the lowest in 1995 (during a house price bust).

\section{B Additional Model Details}

\section{B.1 Conditional Expectation of Total Surplus (П)}

In this subsection, we define $\Pi^{j, k}$, which denotes the expected value of the total surplus associated with a transaction between a type $j$ buyer and a type $k$ seller conditional on the total surplus being greater than zero, multiplied by the probability that the total surplus is greater than zero. The first step is to define the total surplus from each type of transaction in the economy in terms of the value functions defined in the main text:

1. $b$ meets with $b s$

- $T S^{b, b s}=U^{m}-V^{b}+\tilde{\epsilon}+V^{b}-V^{b s}$

2. $b$ buys from $s$

- $T S^{b, s}=U^{m}-V^{b}+\tilde{\epsilon}+\frac{u_{O}}{1-\beta}-V^{s}$

3. $b$ buys from $m s$

- $T S^{b, m s}=U^{m}-V^{b}+\tilde{\epsilon}+V^{m}-V^{m s}$

4. $b$ buys from $s s$

- $T S^{b, s s}=U^{m}-V^{b}+\tilde{\epsilon}+V^{s}-V^{s s}$

5. bs buys from bs

- $T S^{b s, b s}=U^{m s}-V^{b s}+\tilde{\epsilon}+V^{b}-V^{b s}$

6. bs buys from $s$ 
- $T S^{b s, s}=U^{m s}-V^{b s}+\tilde{\epsilon}+\frac{u_{O}}{1-\beta}-V^{s}$

7. $b s$ buys from $m s$

- $T S^{b s, m s}=U^{m s}-V^{b s}+\tilde{\epsilon}+V^{m}-V^{m s}$

8. bs buys from $s s$

- $T S^{b s, s s}=U^{m s}-V^{b s}+\tilde{\epsilon}+V^{s}-V^{s s}$

The only idiosyncratic component to the total surplus is the normally distributed term, $\tilde{\epsilon}$. Let $\overline{T S}$ denote the non-idiosyncratic component of $T S$; that is, $\overline{T S}$ equals $T S$ less a mean zero, idiosyncratic term. Then, using properties of the truncated normal distribution, we can write

$$
\Pi^{j, k}=E\left[T S^{j, k} \mid T S^{j, k}>0\right] \operatorname{Pr}\left(T S^{j, k}>0\right)=\Phi\left(\frac{\overline{T S}^{j, k}}{\tilde{\sigma}}\right) \overline{T S}^{j, k}+\phi\left(\frac{\overline{T S}^{j, k}}{\tilde{\sigma}}\right) \tilde{\sigma}
$$

where $\Phi$ and $\phi$ are the standard normal cdf and pdf, respectively.

\section{B.2 Behavior of a buyer-seller when matched with both a buyer and a seller $\left(d^{\text {sell }}\right)$}

In this subsection, we define the expected value of proceeding as a buyer and as a seller conditional on matching with a buyer and a seller for a member of $b s$. When presenting the value functions, we used $d^{\text {sell }}=1$ to denote the case where the expected value of proceeding as a seller is higher than the expected value of proceeding as a buyer. Since we focus on a symmetric equilibrium, $d^{\text {sell }}$ must be the same for all agents in the economy. Therefore, if the agent chooses to pursue the match as a seller, in equilibrium the expected payoff is

$E($ sell $)=\frac{b}{B}\left(\Phi\left(\frac{\overline{T S}^{b, b s}}{\tilde{\sigma}}\right) \overline{T S}^{b, b s}+\phi\left(\frac{\overline{T S}^{b, b s}}{\tilde{\sigma}}\right) \tilde{\sigma}\right)+\frac{b s}{B}\left(\Phi\left(\frac{\overline{T S}^{b s, b s}}{\tilde{\sigma}}\right) \overline{T S}^{b s, b s}+\phi\left(\frac{\overline{T S}^{b s, b s}}{\tilde{\sigma}}\right) \tilde{\sigma}\right)\left(1-\frac{M}{S}\right)$

If the agent chooses to pursue the match as a buyer, in equilibrium the expected payoff is 


$$
\begin{gathered}
E(\text { buy })=\frac{m s}{S}\left(\Phi\left(\frac{\overline{T S}^{b s, m s}}{\tilde{\sigma}}\right)\left(\overline{T S}^{b s, m s}\right)+\phi\left(\frac{\overline{T S}^{b s, m s}}{\tilde{\sigma}}\right) \tilde{\sigma}\right)+\frac{s}{S}\left(\Phi\left(\frac{\overline{T S}^{b s, s}}{\tilde{\sigma}}\right)\left(\overline{T S}^{b s, s}\right)+\phi\left(\frac{\overline{T S}^{b s, s}}{\tilde{\sigma}}\right) \tilde{\sigma}\right)+ \\
\frac{2 s s}{S}\left(\Phi\left(\frac{\overline{T S}^{b s, s s}}{\tilde{\sigma}}\right)\left(\overline{T S}^{b s, s s}\right)+\phi\left(\frac{\overline{T S}^{b s, s s}}{\tilde{\sigma}}\right) \tilde{\sigma}\right)\left(1-\frac{M}{2 S}\right)+\frac{b s}{S}\left(\Phi\left(\frac{\overline{T S}^{b s, b s}}{\tilde{\sigma}}\right)\left(\overline{T S}^{b s, b s}\right)+\phi\left(\frac{\overline{T S}^{b s, b s}}{\tilde{\sigma}}\right) \tilde{\sigma}\right)\left(1-\frac{M}{B}\right)
\end{gathered}
$$

Note that

$$
d^{\text {sell }}=I[E(\text { sell })>E(\text { buy })]
$$

where $I$ is the indicator function. We have suppressed the dependence on the state in the equations above, but it should be emphasized that $d^{\text {sell }}$ does indeed depend on the state $\Omega_{t}$.

\section{B.3 Equilibrium Transaction Volume}

When $d^{\text {sell }}\left(\Omega_{t}\right)=1$, transaction volume in period $t$ is:

$$
\begin{gathered}
\text { Transaction Volume: } \frac{M}{B * S}\left(b s * b s\left(1-\frac{M}{S}\right) \Phi\left(\frac{\overline{T S}_{b s, b s}}{\tilde{\sigma}}\right)+b s * s\left(1-\frac{M}{S}\right) \Phi\left(\frac{\overline{T S}_{b s, s}}{\tilde{\sigma}}\right)+\right. \\
b s * m s\left(1-\frac{M}{S}\right) \Phi\left(\frac{\overline{T S}_{b s, m s}}{\tilde{\sigma}}\right)+b s * 2 s s\left(1-\frac{M}{S}\right)\left(1-\frac{M}{2 S}\right) \Phi\left(\frac{\overline{T S}_{b s, s s}}{\tilde{\sigma}}\right)+ \\
\left.b * b s \Phi\left(\frac{\overline{T S}_{b, b s}}{\tilde{\sigma}}\right)+b * s \Phi\left(\frac{\overline{T S}_{b, s}}{\tilde{\sigma}}\right)+b * m s \Phi\left(\frac{\overline{T S}_{b, m s}}{\tilde{\sigma}}\right)+b * 2 s s\left(1-\frac{M}{2 S}\right) \Phi\left(\frac{\overline{T S}_{b, s s}}{\tilde{\sigma}}\right)\right)
\end{gathered}
$$

When $d^{\text {sell }}\left(\Omega_{t}\right)=0$, transaction volume is:

$$
\begin{gathered}
\text { Transaction Volume: } \frac{M}{B * S}\left(b s * b s\left(1-\frac{M}{B}\right) \Phi\left(\frac{\overline{T S}_{b s, b s}}{\tilde{\sigma}}\right)+b s * s \Phi\left(\frac{\overline{T S}_{b s, s}}{\tilde{\sigma}}\right)+\right. \\
b s * m s \Phi\left(\frac{\overline{T S}_{b s, m s}}{\tilde{\sigma}}\right)+b s * 2 s s\left(1-\frac{M}{2 S}\right) \Phi\left(\frac{\overline{T S}_{b s, s s}}{\tilde{\sigma}}\right)+ \\
\left.b * b s s\left(1-\frac{M}{B}\right) \Phi\left(\frac{\overline{T S}_{b, b s}}{\tilde{\sigma}}\right)+b * s \Phi\left(\frac{\overline{T S}_{b, s}}{\tilde{\sigma}}\right)+b * m s \Phi\left(\frac{\overline{T S}_{b, m s}}{\tilde{\sigma}}\right)+b * 2 s s\left(1-\frac{M}{2 S}\right) \Phi\left(\frac{\overline{T S}_{b, s s}}{\tilde{\sigma}}\right)\right)
\end{gathered}
$$

\section{B.4 Laws of Motion}

In equilibrium, the state variables transition according to the following equations: 
- When $d^{\text {sell }}\left(\Omega_{t}\right)=1$ :

$$
\begin{aligned}
& b^{\prime}=b-b \frac{M}{B * S}\left(m s \Phi\left(\frac{\overline{T S}_{b, m s}}{\tilde{\sigma}}\right)+s \Phi\left(\frac{\overline{T S}_{b, s}}{\tilde{\sigma}}\right)+2 s s\left(1-\frac{M}{2 S}\right) \Phi\left(\frac{\overline{T S}_{b, s s}}{\tilde{\sigma}}\right)\right) \\
& +b s * b s \frac{M}{B * S}\left(1-\frac{M}{S}\right) \Phi\left(\frac{\overline{T S}_{b s, b s}}{\tilde{\sigma}}\right) \\
& m s^{\prime}=m s-m s \frac{M}{B * S} b \Phi\left(\frac{\overline{T S}_{b, m s}}{\tilde{\sigma}}\right)+b s \frac{M}{B * S}\left(1-\frac{M}{S}\right) \\
& *\left(b s \Phi\left(\frac{\overline{T S}_{b s, b s}}{\tilde{\sigma}}\right)+s \Phi\left(\frac{\overline{T S}_{b s, s}}{\tilde{\sigma}}\right)+2 s s\left(1-\frac{M}{2 S}\right) \Phi\left(\frac{\overline{T S}_{b s, s s}}{\tilde{\sigma}}\right)\right) \\
& s^{\prime}=s-s \frac{M}{B * S}\left(b \Phi\left(\frac{\overline{T S}_{b, s}}{\tilde{\sigma}}\right)+b s\left(1-\frac{M}{S}\right) \Phi\left(\frac{\overline{T S}_{b s, s}}{\tilde{\sigma}}\right)\right)+ \\
& 2 s s \frac{M}{B * S}\left(1-\frac{M}{2 S}\right)\left(b \Phi\left(\frac{\overline{T S}_{b, s s}}{\tilde{\sigma}}\right)+b s\left(1-\frac{M}{S}\right) \Phi\left(\frac{\overline{T S}_{b s, s s}}{\tilde{\sigma}}\right)\right) \\
& s s^{\prime}=s s-2 s s \frac{M}{B * S}\left(1-\frac{M}{2 S}\right)\left(b \Phi\left(\frac{\overline{T S}_{b, s s}}{\tilde{\sigma}}\right)+b s\left(1-\frac{M}{S}\right) \Phi\left(\frac{\overline{T S}_{b s, s s}}{\tilde{\sigma}}\right)\right) \\
& b s^{\prime}=b s-b s \frac{M}{B * S}\left(1-\frac{M}{S}\right)\left(2 b s \Phi\left(\frac{\overline{T S}_{b s, b s}}{\tilde{\sigma}}\right)+m s \Phi\left(\frac{\overline{T S}_{b s, m s}}{\tilde{\sigma}}\right)+\right. \\
& \left.s \Phi\left(\frac{\overline{T S}_{b s, s}}{\tilde{\sigma}}\right)+2 s s\left(1-\frac{M}{2 S}\right) \Phi\left(\frac{\overline{T S}_{b s, s s}}{\tilde{\sigma}}\right)\right)-b s * b * \frac{M}{B * S} \Phi\left(\frac{\overline{T S}_{b, b s}}{\tilde{\sigma}}\right)
\end{aligned}
$$

- When $d^{\text {sell }}\left(\Omega_{t}\right)=0$ :

$$
\begin{aligned}
& b^{\prime}=b-b \frac{M}{B * S}\left(m s \Phi\left(\frac{\overline{T S}_{b, m s}}{\tilde{\sigma}}\right)+s \Phi\left(\frac{\overline{T S}_{b, s}}{\tilde{\sigma}}\right)+2 s s\left(1-\frac{M}{2 S}\right) \Phi\left(\frac{\overline{T S}_{b, s s}}{\tilde{\sigma}}\right)\right) \\
& +b s * b s \frac{M}{B * S}\left(1-\frac{M}{B}\right) \Phi\left(\frac{\overline{T S}_{b s, b s}}{\tilde{\sigma}}\right) \\
& m s^{\prime}=m s-m s \frac{M}{B * S} b \Phi\left(\frac{\overline{T S}_{b, m s}}{\tilde{\sigma}}\right)+b s \frac{M}{B * S} \\
& *\left(b s\left(1-\frac{M}{B}\right) \Phi\left(\frac{\overline{T S}_{b s, b s}}{\tilde{\sigma}}\right)+s \Phi\left(\frac{\overline{T S}_{b s, s}}{\tilde{\sigma}}\right)+2 s s\left(1-\frac{M}{2 S}\right) \Phi\left(\frac{\overline{T S}_{b s, s s}}{\tilde{\sigma}}\right)\right) \\
& s^{\prime}=s-s \frac{M}{B * S}\left(b \Phi\left(\frac{\overline{T S}_{b, s}}{\tilde{\sigma}}\right)+b s \Phi\left(\frac{\overline{T S}_{b s, s}}{\tilde{\sigma}}\right)\right)+ \\
& 2 s s \frac{M}{B * S}\left(1-\frac{M}{2 S}\right)\left(b \Phi\left(\frac{\overline{T S}_{b, s s}}{\tilde{\sigma}}\right)+b s \Phi\left(\frac{\overline{T S}_{b s, s s}}{\tilde{\sigma}}\right)\right) \\
& s s^{\prime}=s s-2 s s \frac{M}{B * S}\left(1-\frac{M}{2 S}\right)\left(b \Phi\left(\frac{\overline{T S}_{b, s s}}{\tilde{\sigma}}\right)+b s \Phi\left(\frac{\overline{T S}_{b s, s s}}{\tilde{\sigma}}\right)\right) \\
& b s^{\prime}=b s-b s \frac{M}{B * S}\left(2 b s\left(1-\frac{M}{B}\right) \Phi\left(\frac{\overline{T S}_{b s, b s}}{\tilde{\sigma}}\right)+m s \Phi\left(\frac{\overline{T S}_{b s, m s}}{\tilde{\sigma}}\right)+\right. \\
& \left.s \Phi\left(\frac{\overline{T S}_{b s, s}}{\tilde{\sigma}}\right)+2 s s\left(1-\frac{M}{2 S}\right) \Phi\left(\frac{\overline{T S}_{b s, s s}}{\tilde{\sigma}}\right)\right)-b s * b * \frac{M}{B * S}\left(1-\frac{M}{B}\right) \Phi\left(\frac{\overline{T S}_{b, b s}}{\tilde{\sigma}}\right)
\end{aligned}
$$


- Exogenous movements due to mismatch shocks

$$
\begin{aligned}
& m s^{\prime}=m s-\lambda m s \\
& s s^{\prime}=s s+\lambda m s \\
& s^{\prime}=s+\lambda(1-\pi)(1-b s-2 m s-s-2 s s) \\
& b s^{\prime}=b s+\lambda \pi(1-b s-2 m s-s-2 s s) \\
& b^{\prime}=b+\gamma
\end{aligned}
$$

\section{B.5 Welfare}

Social welfare in our model economy is defined as follows:

$$
\begin{aligned}
W & =\sum_{t=0}^{\infty} \beta^{t} E\left(b s_{t} u_{m m}+\left(m s_{t}+s s_{t}\right)\left(-u_{d}\right)+\left(s_{t}+s s_{t}\right) u_{m m o}+b_{t} u_{b}+\frac{M\left(B_{t}, S_{t}\right)}{B_{t} S_{t}}(\right. \\
& +b s_{t} b s_{t} \Phi\left(\frac{\tilde{\epsilon}_{b s, b s}^{*}-\tilde{u}_{m}}{\tilde{\sigma}}\right) E\left[\tilde{\epsilon} \mid \tilde{\epsilon}>\tilde{\epsilon}_{b s, b s}^{*}\right]\left(1-d_{t}^{\text {sell }} \frac{M\left(B_{t}, S_{t}\right)}{S_{t}}\right) \\
& +b s_{t} s_{t} \Phi\left(\frac{\tilde{\epsilon}_{b s, s}^{*}-\tilde{u}_{m}}{\tilde{\sigma}}\right)\left(E\left[\tilde{\epsilon} \mid \tilde{\epsilon}>\tilde{\epsilon}_{b s, s}^{*}\right]+V^{O}\right)\left(1-d_{t}^{\text {sell }} \frac{M\left(B_{t}, S_{t}\right)}{S_{t}}\right) \\
& +b s_{t} m s_{t} \Phi\left(\frac{\tilde{\epsilon}_{b s, m s}^{*}-\tilde{u}_{m}}{\tilde{\sigma}}\right) E\left[\tilde{\epsilon} \mid \tilde{\epsilon}>\tilde{\epsilon}_{b s, m s}^{*}\right]\left(1-d_{t}^{s e l l} \frac{M\left(B_{t}, S_{t}\right)}{S_{t}}\right) \\
& +b_{t} b s_{t} \Phi\left(\frac{\tilde{\epsilon}_{b, b s}^{*}-\tilde{u}_{m}}{\tilde{\sigma}}\right) E\left[\tilde{\epsilon} \mid \tilde{\epsilon}>\tilde{\epsilon}_{b, b s}^{*}\right]\left(1-\left(1-d_{t}^{s e l l}\right) \frac{M\left(B_{t}, S_{t}\right)}{B_{t}}\right) \\
& +b_{t} s_{t} \Phi\left(\frac{\tilde{\epsilon}_{b, s}^{*}-\tilde{u}_{m}}{\tilde{\sigma}}\right)\left(E\left[\tilde{\epsilon} \mid \tilde{\epsilon}>\tilde{\epsilon}_{b, s}^{*}\right]+V^{O}\right)+b_{t} m s_{t} \Phi\left(\frac{\tilde{\epsilon}_{b, m s}^{*}-\tilde{u}_{m}}{\tilde{\sigma}}\right) E\left[\tilde{\epsilon} \mid \tilde{\epsilon}>\tilde{\epsilon}_{b, m s}^{*}\right] \\
& +2 b_{t} s s_{t} \Phi\left(\frac{\tilde{\epsilon}_{b, s s}^{*}-\tilde{u}_{m}}{\tilde{\sigma}}\right) E\left[\tilde{\epsilon} \mid \tilde{\epsilon}>\tilde{\epsilon}_{b, s s}^{*}\right]\left(1-\frac{M\left(B_{t}, S_{t}\right)}{2 S_{t}}\right) \\
& \left.\left.+2 b s_{t} s s_{t} \Phi\left(\frac{\tilde{\epsilon}_{b s, s s}^{*}-\tilde{u}_{m}}{\tilde{\sigma}}\right) E\left[\tilde{\epsilon} \mid \tilde{\epsilon}>\tilde{\epsilon}_{b s, s s}^{*}\right]\left(1-\frac{M\left(B_{t}, S_{t}\right)}{2 S_{t}}\right)\left(1-d_{t}^{s e l l} \frac{M\left(B_{t}, S_{t}\right)}{S_{t}}\right)\right)\right)
\end{aligned}
$$

$\tilde{\epsilon}_{k, j}^{*}$ is the match quality threshold for a transaction to occur between a type $k$ buyer and a type $j$ seller. We suppress the dependence on the state, $\left(\Omega_{t}\right)$, but in both the decentralized and the centralized equilibrium, the threshold will depend on $\left(\Omega_{t}\right)$. $\Phi$ is the normal cdf, and the $\Phi$ terms represent the probability that the match quality exceeds the threshold, conditional on a match occurring. $E\left[\tilde{\epsilon} \mid \tilde{\epsilon}>\tilde{\epsilon}^{*}\right]$ represents the expected match quality draw conditional on the match quality exceeding the threshold.

Note that the total discounted present value of the entire steam of $\epsilon$ shocks is accounted for at the time of the transaction. We can express welfare in these terms because the expected 
duration of a match is constant and exogenous in the model. The outer expectation in (24) is with respect to realizations of the inflow process. The $V^{O}$ term reflects the fact that when there is a transaction involving an external seller, a lifetime utility of $V^{O}$ is also generated for an agent that exits the city. Prices do not enter (24) because they are simply transfers from one agent to another. 
Figure 1: Los Angeles Prices, Volume, Time on Market

Real house price and total transaction volume index based on Dataquick data. Median time on market from California Association of Realtors. The underlying data are presented in Table 1.

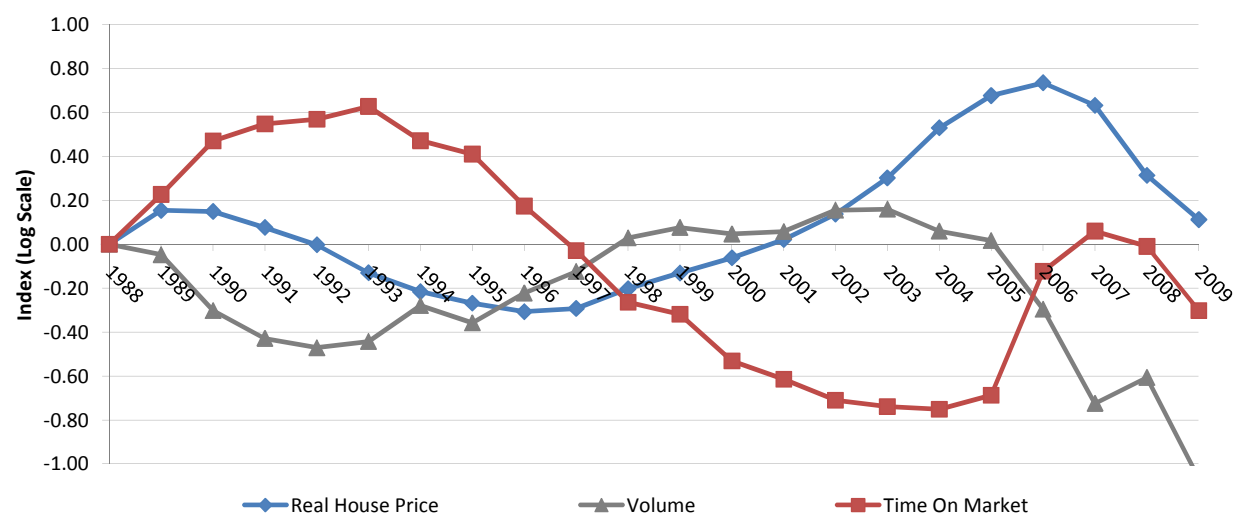


Figure 2: Los Angeles Transaction Volume by Type

The underlying data (from Dataquick) are presented in Table 1. A transaction is internal if the seller bought a house in the Los Angeles MSA within twelve months of the selling date. Otherwise, it is external.

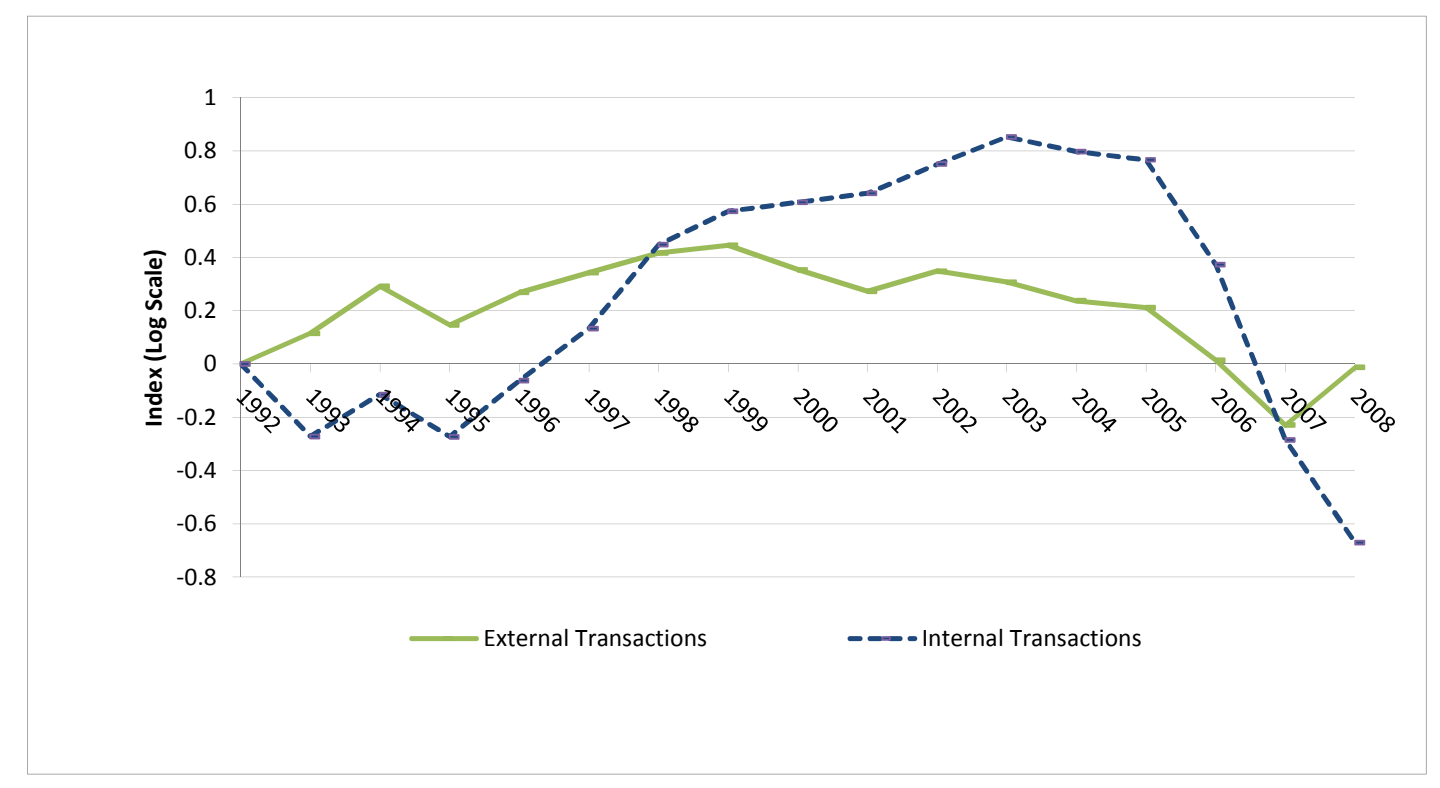




\section{Figure 3: Distribution of Sell Date - Purchase Date for Internal Movers}

Histogram of days between sale and purchase for internal movers in Los Angeles for years 1992-2008 calculated using Dataquick.

A mover is internal if he sells one house and buys another within the Los Angeles MSA within twelve months of each other.

Date of buy and sell are defined using closing dates.

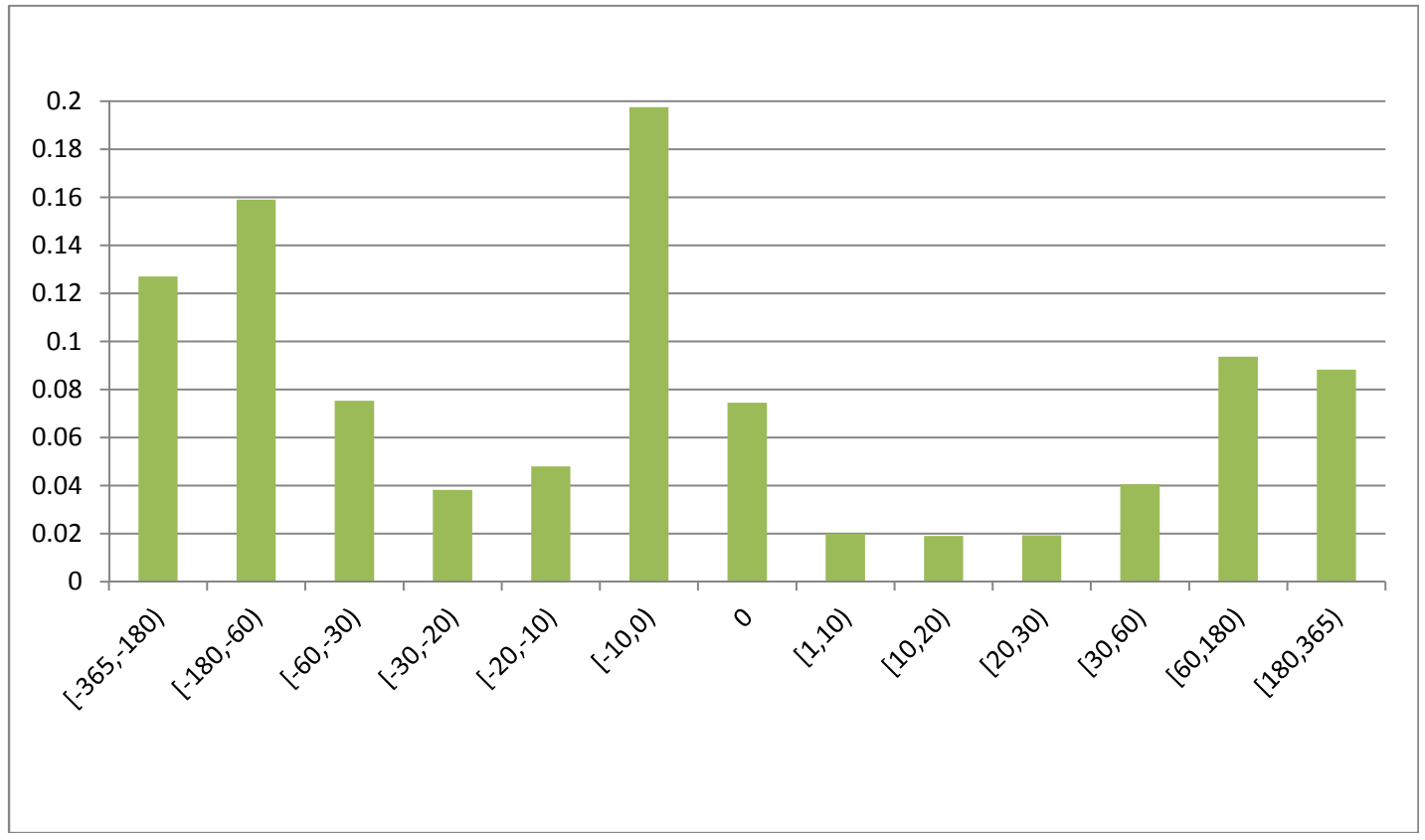




\section{Figure 4: Internal Mover Share by LTV}

This graph shows the share of transactions by internal movers when we restrict the sample by the loan-to-value (LTV) ratio of the seller at the time of the sale (calculated using Dataquick data). LTV is imputed, as described in the main text, using data on the original loan amount (including all mortgages), refinances, and the original purchase price. A transaction is internal if the seller bought a house in the Los Angeles MSA within twelve months of the selling date.

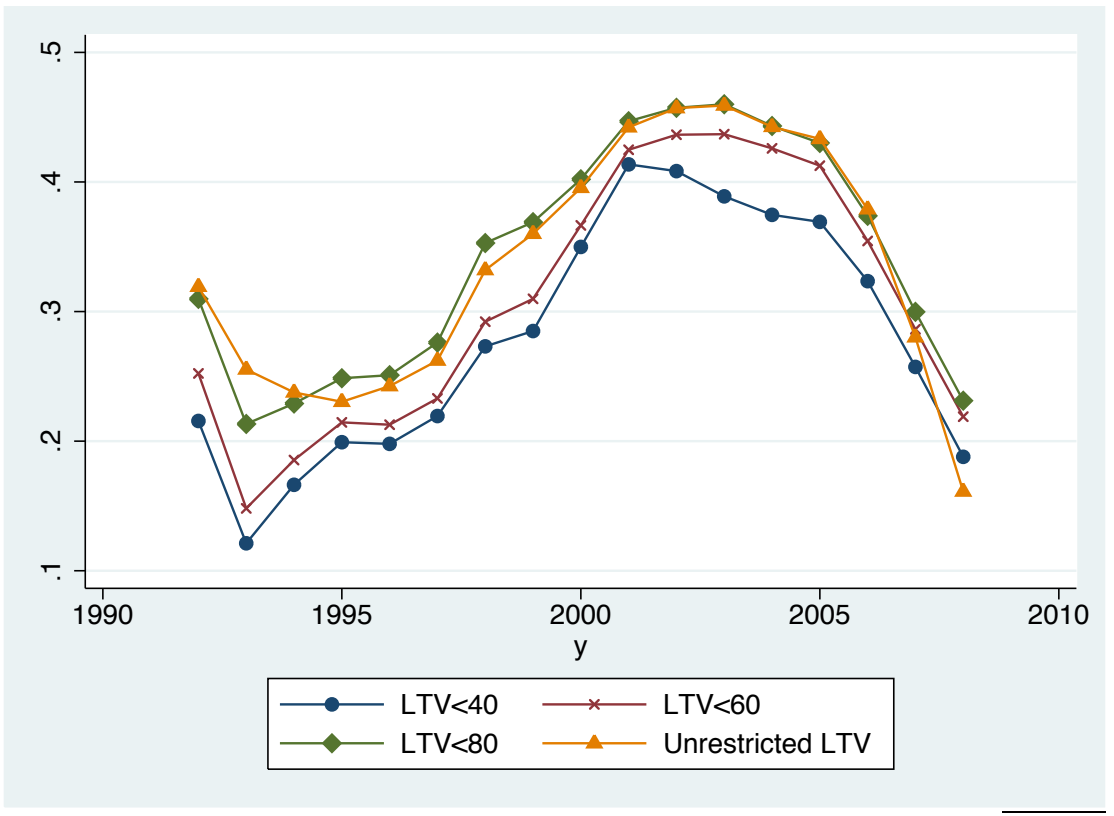




\section{Figure 5: Internal Mover Share, Excluding Flippers}

This graph reproduces the time-series of the internal mover on a subset of the main sample, which excludes all transactions purchased by buyers who buy multiple homes within the calendar year. A transaction is internal if the seller bought a house in the Los Angeles MSA within twelve months of the selling date.

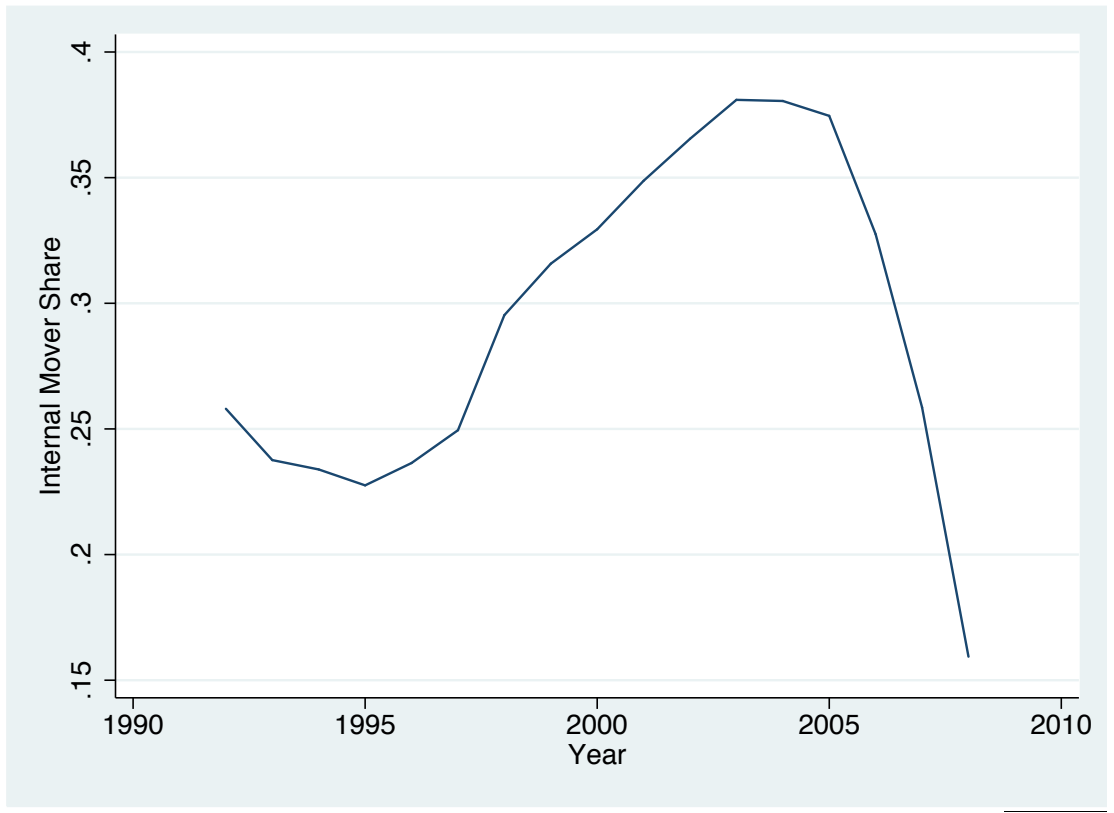




\section{Figure 6: Flow Chart of Model Economy}

This figure shows how agents in the model economy flow through the different pools. Double arrows reflect endogenous movements through trade and single arrows reflect exogenous movements. The greek letters in italics to the right of the single arrows reflect the probability that the exogenous movement occurs. $b$ denotes a buyer; $m$ denotes a matched owner; $b s$ denotes a buyer-seller; $m s$ denotes a dual position seller; $s$ denotes an external seller; $s s$ denotes a dual position external seller.

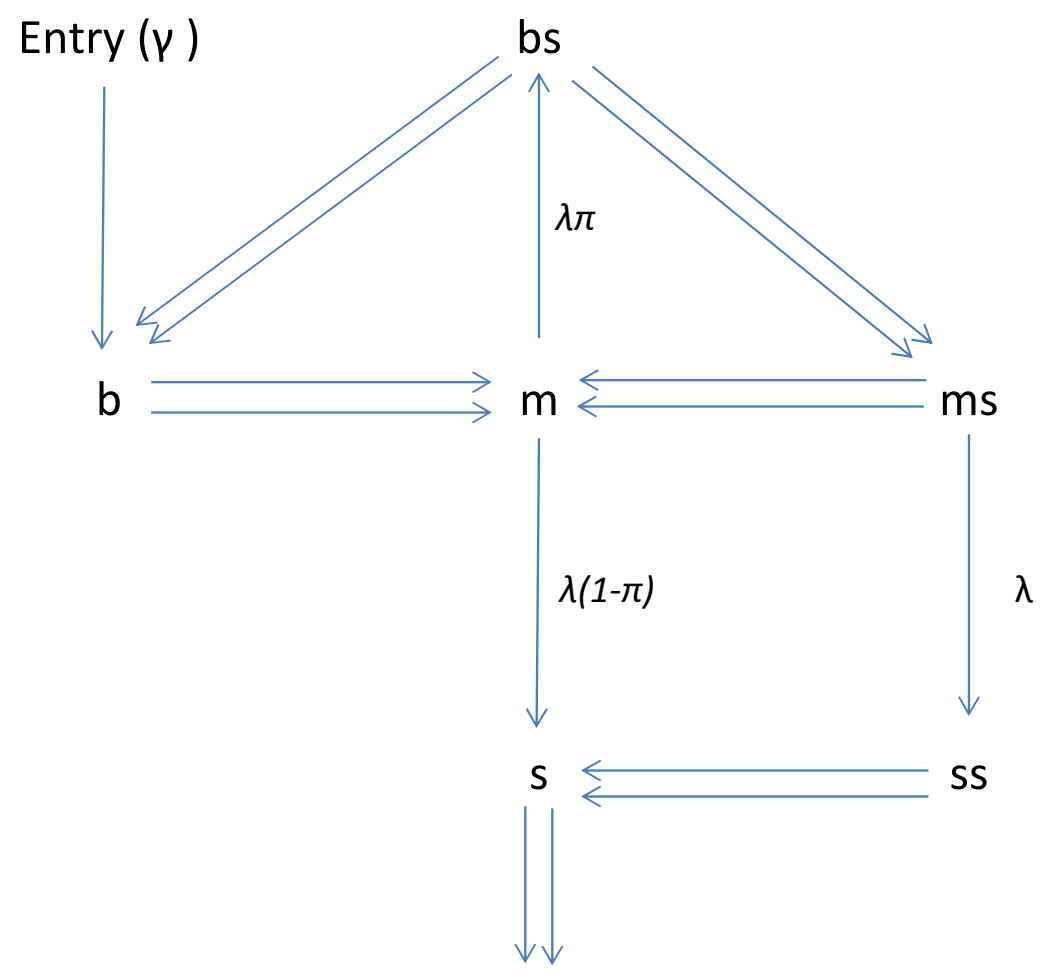

Exit 


\section{Figure 7: Simulated Mismatch over the House Price Cycle}

This figure illustrates how the estimated model generates endogenous build-ups and release of mismatched homeowners over time. Internal mismatch (buyer-sellers (bs) and dual position sellers (ms)) and external mismatch (external sellers (s) and dual position external sellers (ss)) are plotted for an arbitrary, but representative 20 year simulation on the left y-axis. The average house price is plotted on the right y-axis, where the house price in period one is indexed to one.

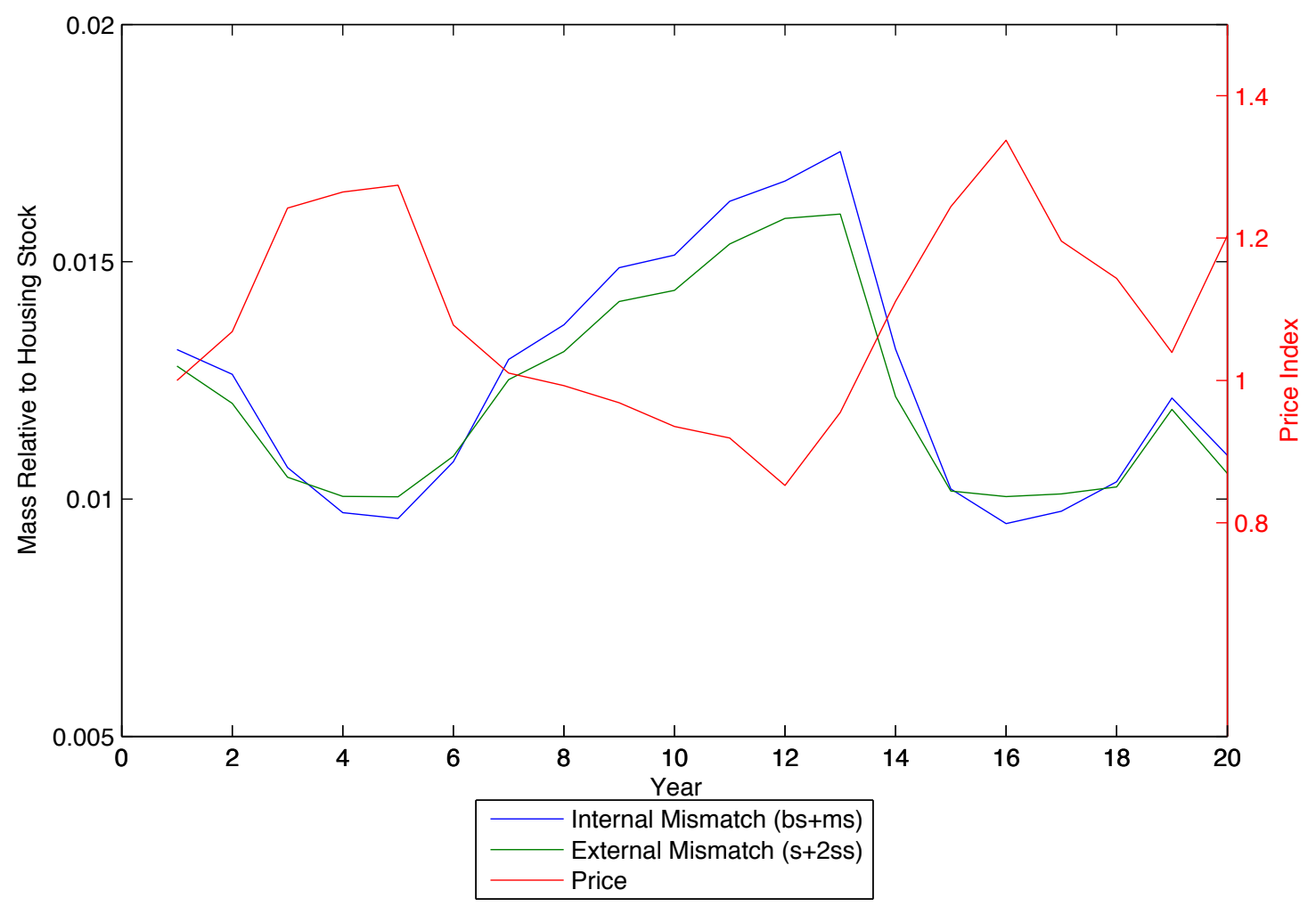




\section{Figure 8: Simulated Price Index Under Counterfactual Models Relative to Baseline Model}

This figure compares the price dynamics for a 20-year period (one in which the inflow realizations are such that there is a large boom and bust in the baseline model) in the baseline model, the model without internal movement, and the model in which $u_{d}$ is lowered to $-1 / 2 u_{m m}$. Prices are indexed to one in period one.

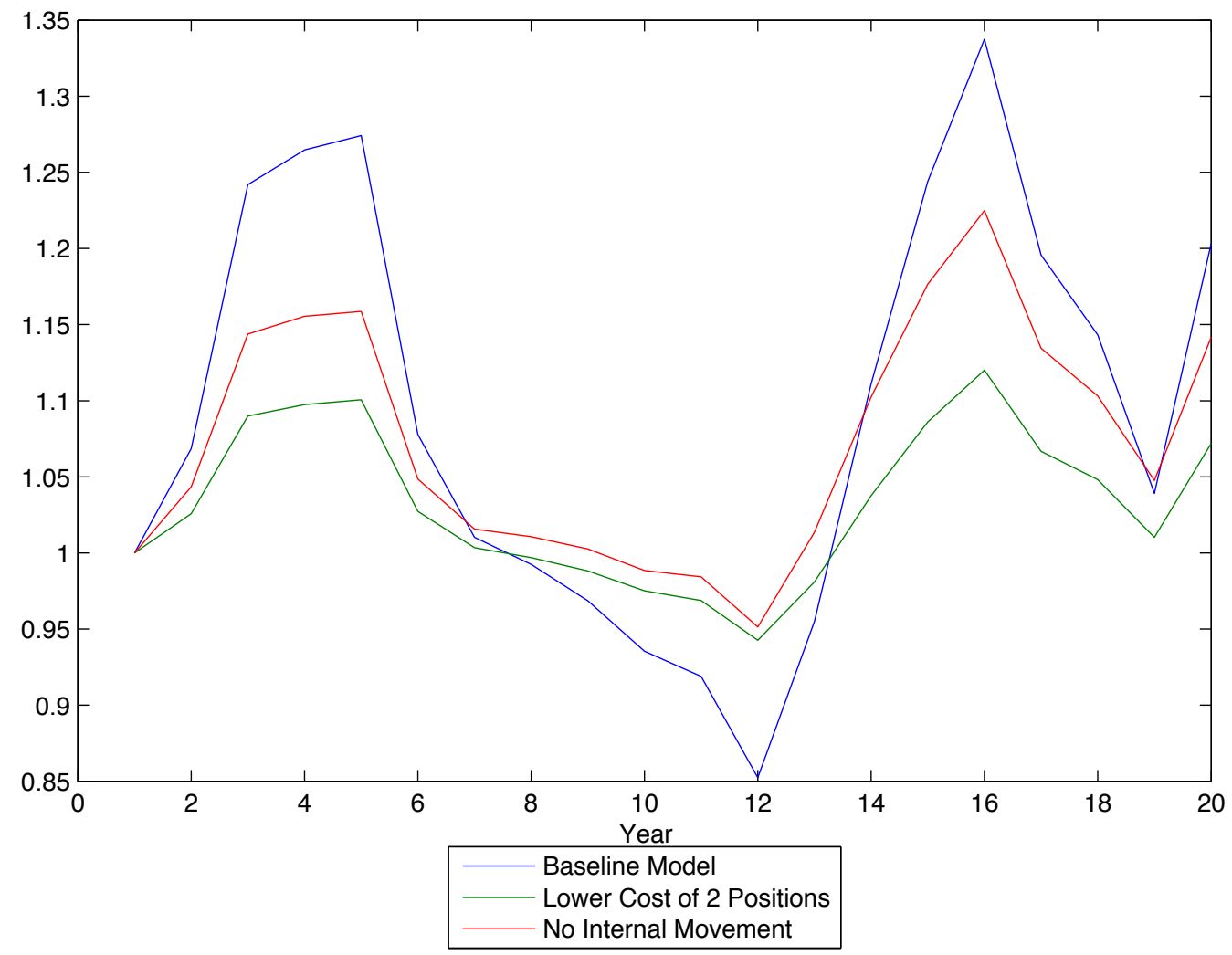




\section{Figure 9: Simulated Mismatch Under Counterfactual Models Relative to Baseline Model}

This figure compares the mismatch dynamics in the baseline model relative to the counterfactual model where $u_{d}$ is lowered to $-1 / 2 u_{m m}$ for a 20 -year period (one in which the inflow realizations are such that there is a large boom and bust in the baseline model). Indexes summarizing price dynamics in each of the two models are plotted on the left y-axis. The pool labeled mismatch consists of buyer-sellers (bs), external sellers (s), and dual position external sellers (ss).

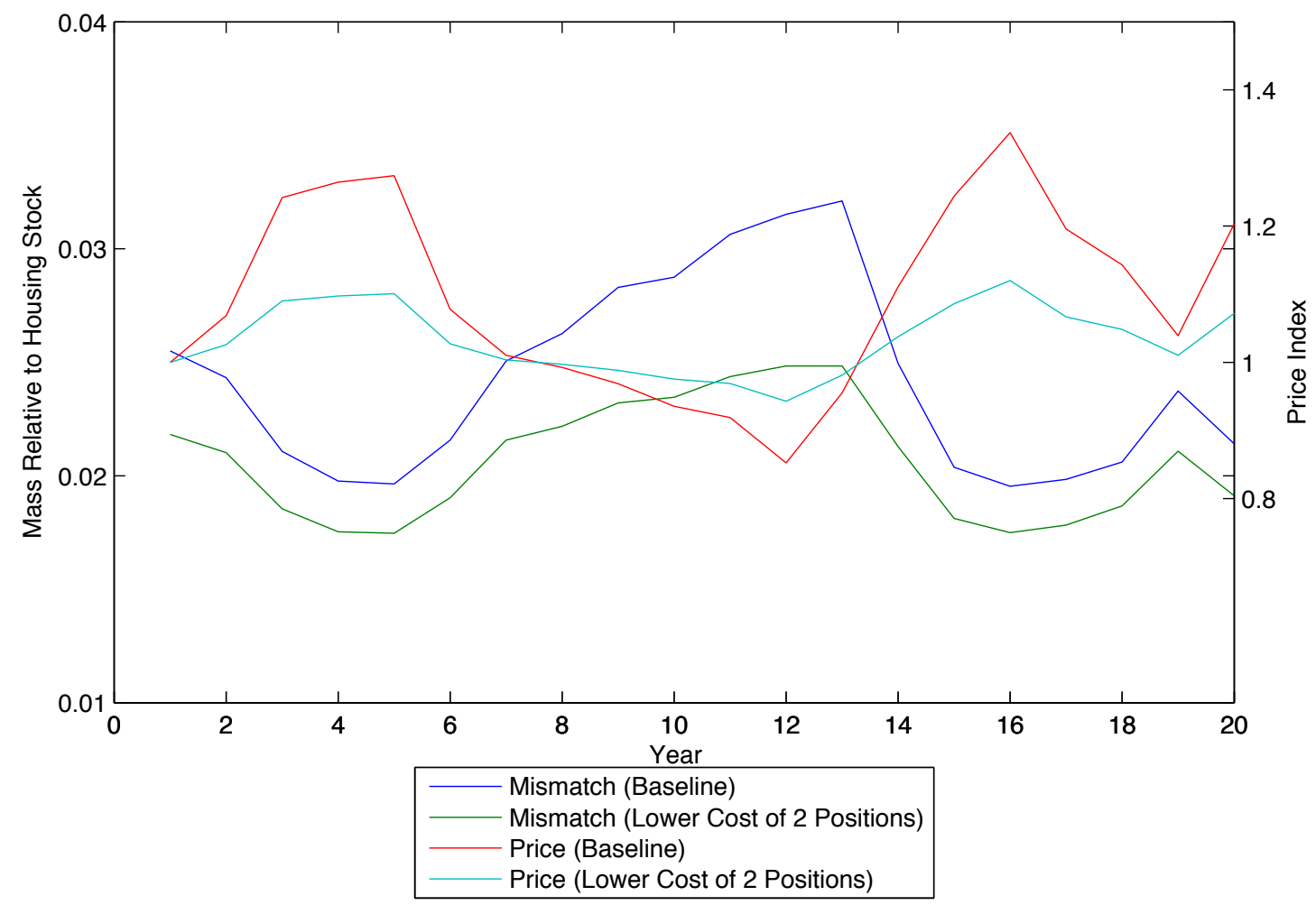


Figure A1: Internal mover share is the share of moves into owner occupancy where the previous home for the owner occupant was in the same MSA and also owner occupied. Owner occupancy is inferred from the mortgage information of the individual. See Appendix for additional details. The source for internal mover share is Equifax and the source for house price index is CoreLogic.
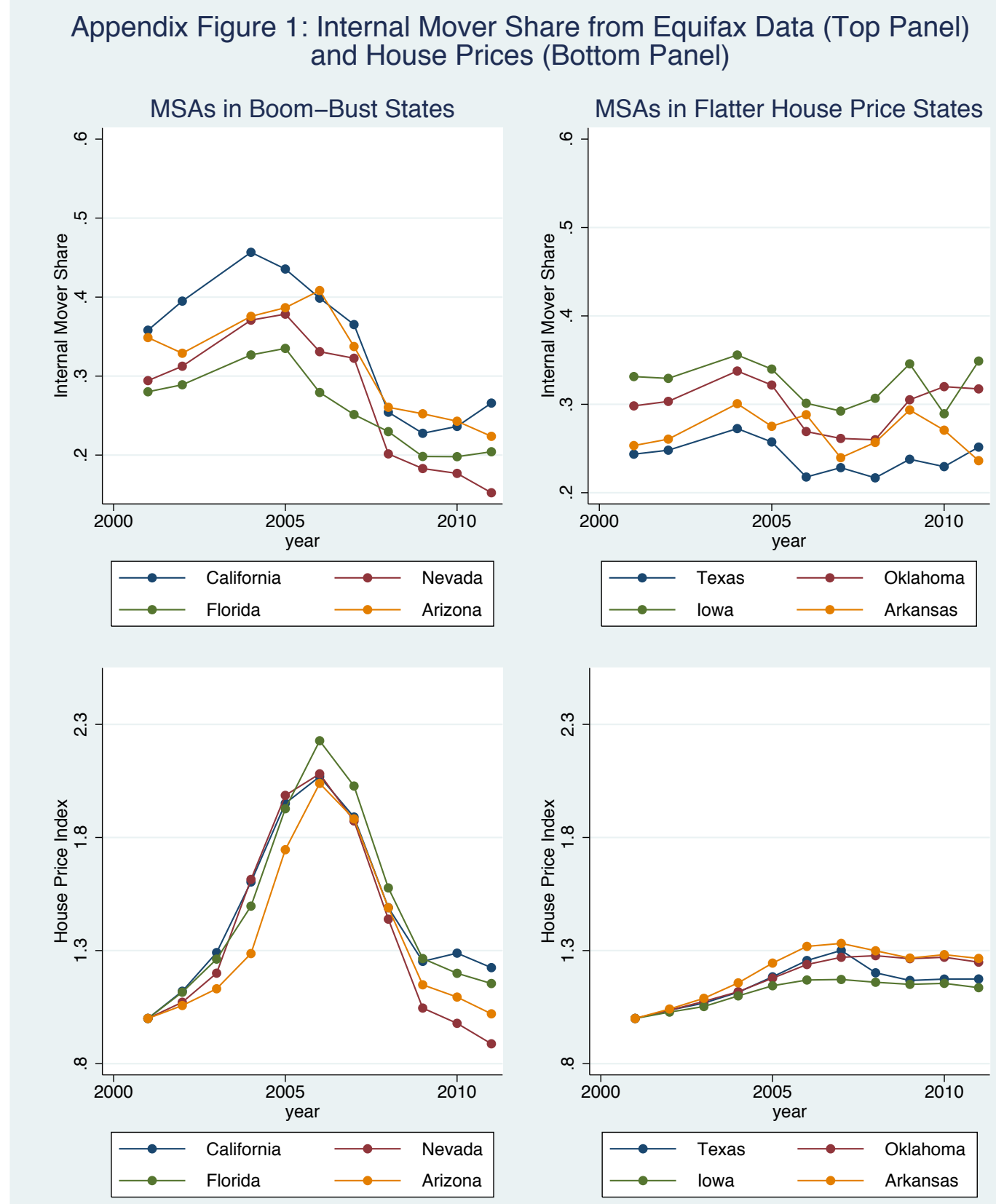

Notes: Internal mover share is the share of moves into owner occupancy where the previous home for the owner occupant was in the same MSA and also owner occupied. See Appendix for additional details. The source for internal mover share is Equifax and the source for house price index is CoreLogic. 
Table 1: Summary Of Transactions and Prices, Los Angeles Metropolitan Area 1988-2009

Year 2009 includes sales through June only. A transaction is internal if the seller also bought a house in the Los Angeles MSA within 12 months of the selling date. A transaction is external if the seller does not buy a house in the Los Angeles MSA within 12 months of the selling date. All data except for Days on Market comes from Dataquick. Days on Market data comes from California Association of Realtors. We cannot break out total transaction volume into internal and external movement during the years before 1992 because the buyer and seller names are severely truncated in the Dataquick data for those years.

\begin{tabular}{ccccccc} 
Year & $\begin{array}{c}\text { Real House } \\
\text { Price Index }\end{array}$ & $\begin{array}{c}\text { Total } \\
\text { Transactions }\end{array}$ & $\begin{array}{c}\text { Median Days } \\
\text { on Market }\end{array}$ & $\begin{array}{c}\text { External } \\
\text { Transactions }\end{array}$ & $\begin{array}{c}\text { Internal } \\
\text { Transactions }\end{array}$ & $\begin{array}{c}\text { Internal Mover } \\
\text { Share }\end{array}$ \\
\hline 1988 & 0.00 & 225,103 & 50 & -- & -- & -- \\
1989 & 0.15 & 214,682 & 62 & -- & -- & -- \\
1990 & 0.15 & 166,434 & 80 & -- & -- & -- \\
1991 & 0.08 & 146,592 & 86 & -- & -- & 25.6 \\
1992 & 0.00 & 140,522 & 88 & 104,553 & 35,969 & 22.6 \\
1993 & -0.13 & 144,618 & 93 & 111,919 & 32,699 & 21.6 \\
1994 & -0.22 & 170,250 & 80 & 133,519 & 36,731 & 20.2 \\
1995 & -0.27 & 157,369 & 75 & 125,508 & 31,861 & 21.9 \\
1996 & -0.31 & 180,183 & 59 & 142,621 & 37,562 & 26.7 \\
1997 & -0.29 & 198,838 & 48 & 155,267 & 43,571 & 31.0 \\
1998 & -0.20 & 231,606 & 38 & 169,703 & 61,903 & 33.8 \\
1999 & -0.13 & 242,962 & 36 & 172,311 & 70,651 & 35.7 \\
2000 & -0.06 & 235,843 & 29 & 162,663 & 73,180 & 37.3 \\
2001 & 0.02 & 238,522 & 27 & 157,964 & 80,558 & 38.1 \\
2002 & 0.14 & 262,751 & 24 & 168,975 & 93,776 & 38.1 \\
2003 & 0.30 & 264,161 & 24 & 165,610 & 98,551 & 33.4 \\
2004 & 0.53 & 238,939 & 23 & 147,967 & 90,972 & 24.6 \\
2005 & 0.68 & 228,850 & 25 & 141,588 & 87,262 & -1 \\
2006 & 0.73 & 167,411 & 44 & 111,546 & 55,865 & - \\
2007 & 0.63 & 109,046 & 53 & 82,211 & 26,835 & \\
2008 & 0.31 & 122,698 & 49 & 106,824 & 15,874 & -- \\
2009 & 0.11 & 77,506 & 37 & -- & & \\
\hline
\end{tabular}




\section{Table 2: Effect of Internal Mover Type on Sales Prices}

These regressions investigate how sales prices of homes bought and sold by internal movers depend on the number of days between the sale date and the purchase date, and how the sales prices of homes sold by internal movers compare with the sales prices of homes sold by external movers. The source is the Los Angeles Dataquick data. Log sales price are normalized by a $\log$ predicted market price, which is calculated in a first stage through a repeat sales analysis. Transactions that do not have a previous price during our sample window are thus excluded from the second stage regression. I[] denotes the indicator function. In the first two columns, the sample is restricted to internal movers, so that the price comparisons are between internal movers who buy and sell at various times. A mover is internal if they bought a house in the Los Angeles MSA within 12 months of the selling date and external otherwise. The first column investigates the price of the home sold by internal movers. The second column investigates the price of the home purchased by internal movers. The third column investigates the prices of homes sold by internal movers relative to the prices of homes sold by external movers.

\begin{tabular}{|c|c|c|c|}
\hline & $\begin{array}{c}\text { Log Price - } \\
\text { Log Predicted Price } \\
\text { of Sell }\end{array}$ & $\begin{array}{c}\text { Log Price - } \\
\text { Log Predicted Price } \\
\text { of Buy }\end{array}$ & $\begin{array}{c}\text { Log Price - } \\
\text { Log Predicted Price } \\
\text { of Sell }\end{array}$ \\
\hline I $[60<$ (Sell Date - Purchase Date $)<180]$ & $\begin{array}{c}-0.0103^{* * *} \\
(0.0017)\end{array}$ & $\begin{array}{l}-0.0035 \\
(0.0025)\end{array}$ & \\
\hline $\mathrm{I}[30<($ Sell Date - Purchase Date $)<60]$ & $\begin{array}{c}-0.0080^{* * *} \\
(0.0023)\end{array}$ & $\begin{array}{l}-0.0016 \\
(0.0033)\end{array}$ & \\
\hline $\mathrm{I}[20<($ Sell Date - Purchase Date $)<30]$ & $\begin{array}{c}-0.0129^{* * *} \\
(0.0032)\end{array}$ & $\begin{array}{l}-0.0114^{* *} \\
(0.0045)\end{array}$ & \\
\hline I $[10<$ (Sell Date - Purchase Date $)<20]$ & $\begin{array}{l}-0.0134^{\star * *} \\
(0.0031)\end{array}$ & $\begin{array}{l}-0.0064 \\
(0.0044)\end{array}$ & \\
\hline $\mathrm{I}[0<$ (Sell Date - Purchase Date) $<10]$ & $\begin{array}{c}-0.0099^{* * *} \\
(0.0030)\end{array}$ & $\begin{array}{l}-0.0038 \\
(0.0042)\end{array}$ & \\
\hline I[(Sell Date - Purchase Date) $==0]$ & $\begin{array}{l}0.0132^{* * *} \\
(0.0020)\end{array}$ & $\begin{array}{c}0.0000 \\
(0.0028)\end{array}$ & \\
\hline I $[0<$ (Sell Date - Purchase Date $)<-10]$ & $\begin{array}{l}0.0137^{* * *} \\
(0.0016)\end{array}$ & $\begin{array}{c}0.0002 \\
(0.0022)\end{array}$ & \\
\hline I[ $-20<$ (Sell Date - Purchase Date $)<-10]$ & $\begin{array}{l}0.0185^{\star * *} \\
(0.0022)\end{array}$ & $\begin{array}{c}0.0048 \\
(0.0031)\end{array}$ & \\
\hline I[-30 < (Sell Date - Purchase Date) $<-20]$ & $\begin{array}{l}0.0125^{\star * *} \\
(0.0023)\end{array}$ & $\begin{array}{l}0.0103^{* * *} \\
(0.0033)\end{array}$ & \\
\hline I[-30 < (Sell Date - Purchase Date) $<-60]$ & $\begin{array}{c}0.0133^{* * *} \\
(0.0019)\end{array}$ & $\begin{array}{c}0.0035 \\
(0.0027)\end{array}$ & \\
\hline I[-60 < (Sell Date - Purchase Date) $<-180]$ & $\begin{array}{c}0.0057^{\star * *} \\
(0.0015)\end{array}$ & $\begin{array}{l}-0.0001 \\
(0.0022)\end{array}$ & \\
\hline I[-180 < (Sell Date - Purchase Date) $<-365$ ] & $\begin{array}{c}0.0005 \\
(0.0016)\end{array}$ & $\begin{array}{c}0.0028 \\
(0.0023)\end{array}$ & \\
\hline I[Internal Mover] & & & $\begin{array}{c}0.0530 * * * \\
(0.0006)\end{array}$ \\
\hline $\begin{array}{l}\text { Month Fixed Effects } \\
\text { Sample Includes: }\end{array}$ & $x$ & $x$ & $\mathrm{x}$ \\
\hline $\begin{array}{l}\text { Internal Movers } \\
\text { External Movers }\end{array}$ & $x$ & $\mathrm{x}$ & $\begin{array}{l}x \\
x\end{array}$ \\
\hline Observations & 527454 & 300597 & 1426185 \\
\hline
\end{tabular}




\section{Table 3: Moments Targeted in Estimation}

The means $(\mu)$ and standard deviations $(\sigma)$, as well as the correlation coefficients (Correl), are taken over the time series. All changes are annual.

\begin{tabular}{lcc}
\multicolumn{1}{c}{ Moment } & Data & Simulated Value \\
\hline Median Months on market for sellers $(\mu)$ & 2.000 & 4.042 \\
Median Months on market for sellers $(\sigma / \mu)$ & 0.436 & 0.273 \\
Correl(Median Months on market, $\Delta$ Real Price) & -0.390 & -0.138 \\
Sales volume $(\sigma / \mu)$ & 0.240 & 0.062 \\
Correl(sales volume, $\Delta$ Real Price) & 0.850 & 0.748 \\
Real price $(\sigma / \mu)$ & 0.316 & 0.371 \\
Within-period price dispersion as a share of average price $(\mu)$ & 0.130 & 0.113 \\
Share of internal movers who buy first $(\mu)$ & 0.292 & 0.308 \\
Correl(Share of internal movers who buy first, $\Delta$ Real Price) & 0.000 & -0.017 \\
Correl(Share of transactions by internal movers, $\Delta$ Real Price) & 0.920 & 0.715 \\
External Sellers Price Discount & 0.050 & 0.071 \\
\hline
\end{tabular}

Table 4: Parameter Estimates

Parameters Calibrated A Priori/Normalizations

\begin{tabular}{clc} 
Parameter & \multicolumn{1}{c}{ Description } & Value \\
\hline$\mu_{\mathrm{b}}$ & Monthly Flow utility of being a buyer & 0.0000 \\
$\mu_{\mathrm{m}}$ & Monthly Flow utility of being mismatched & 1.0000 \\
$\beta$ & Monthly Discount factor & 0.9950 \\
$\mu_{\mathrm{infl}}$ & Monthly Average inflow into economy & 0.0053 \\
$\lambda$ & Monthly Probability of transition to mismatch & 0.0083 \\
$\eta$ & Exponent of matching function & 0.8400 \\
$\mathrm{~A}$ & Scaling of matching function & 0.5000 \\
$\theta$ & Bargaining power of seller & 0.5000 \\
$(1-\pi)$ & Share of Mismatched Starter Owners Get Mismatched with City & 0.6667
\end{tabular}

Parameters Estimated by Simulated MOM

\begin{tabular}{clcc} 
Parameter & \multicolumn{1}{c}{ Description } & Estimate & Standard Error \\
\hline$\mu_{\mathrm{mm}}$ & Monthly Flow utility of being matched & 0.9198 & 0.0496 \\
$\mu_{\mathrm{mmo}}$ & Monthly Flow utility of being mismatched with metro area & 0.5438 & 0.0331 \\
$\mu_{\mathrm{d}}$ & Monthly Flow utility penalty of having 2 positions & 0.6133 & 0.0125 \\
$\sigma$ & Stdev. Of match quality shocks & 0.0787 & 0.0115 \\
$\sigma_{\mathrm{infl}}$ & Monthly Stdev of inflow into economy & 0.0021 & 0.0003
\end{tabular}




\section{Table 5: Model Generated Volatility}

Volatility is defined as the coefficient of variation over time. The unit of observation is a year. Volume is total annual sales volume, price is an annual average price (weighted by monthly volume), and TOM is an annual average time on market (weighted by monthly volume). In the no internal movement model, upon selling, sellers receive a time invariant and market conditions invariant lifetime utility. $u_{d}$ denotes the penalty to flow utility from owning two homes. $u_{m m}$ denotes the flow utility associated with being mismatched.

\begin{tabular}{lccccc} 
& & \multicolumn{4}{c}{ Counterfactual Models } \\
\cline { 3 - 6 } & & & \multicolumn{3}{c}{$\mathrm{u}_{\mathrm{d}}$ equals: } \\
\cline { 3 - 6 } Paseline Model & No Internal Movement & & 1/4 of baseline estimate & zero & $-1 / 2^{*} \mathrm{u}_{\mathrm{mm}}$ \\
\cline { 2 - 6 } Prices & 0.371 & 0.121 & 0.3281 & 0.257 & 0.095 \\
Volume & 0.062 & 0.056 & 0.0531 & 0.052 & 0.051 \\
TOM & 0.273 & 0.226 & 0.2182 & 0.211 & 0.208
\end{tabular}

\section{Table 6: Policy and Welfare Analysis}

The policy consists of subsidises to both the per period utility of holding two homes $\left(u_{d}\right)$ and the per period utility of being mismatched with the city $\left(u_{m m o}\right)$, and a tax on each transaction. The subsidies and taxes are chosen optimally so as to maximize social welfare subject to revenue neutrality. Volatility is defined as the coefficient of variation over time. The unit of observation is a year. Volume is total annual sales volume, price is an annual average price (weighted by monthly volume), and TOM is an annual average time on market (weighted by monthly volume).

Change in Welfare per Transaction
Price Volatility
Volume Volatility
TOM Volatility

Change in Welfare per Transaction Volume Volatility

TOM Volatility 
Table A1: Effect of Internal Mover Type on Sales Prices, Alternative Definition of Internal Move

This table reproduces the regressions display in Table 2 but on a sample of internal movers where the definition of an internal mover is more stringent. For a pair of transactions to be an internal move, here we require an exact match between the seller and buyer variables in the transaction data. See Table 2 for additional notes.

\begin{tabular}{|c|c|c|c|}
\hline & $\begin{array}{c}\text { Log Price - } \\
\text { Log Predicted Price } \\
\text { of Sell }\end{array}$ & $\begin{array}{c}\text { Log Price - } \\
\text { Log Predicted Price } \\
\text { of Buy }\end{array}$ & $\begin{array}{c}\text { Log Price - } \\
\text { Log Predicted Price } \\
\text { of Sell }\end{array}$ \\
\hline I $[60<$ (Sell Date - Purchase Date $)<180]$ & $\begin{array}{c}-0.0265^{* * *} \\
(0.0032)\end{array}$ & $\begin{array}{l}-0.0056 \\
(0.0046)\end{array}$ & \\
\hline I[30< (Sell Date - Purchase Date) $<60]$ & $\begin{array}{c}-0.0353^{* * *} \\
(0.0039)\end{array}$ & $\begin{array}{l}-0.0102^{*} \\
(0.0055)\end{array}$ & \\
\hline $\mathrm{I}[20<($ Sell Date - Purchase Date $)<30]$ & $\begin{array}{c}-0.0396^{* * *} \\
(0.0050)\end{array}$ & $\begin{array}{c}-0.0178^{* *} \\
(0.0071)\end{array}$ & \\
\hline I $[10<($ Sell Date - Purchase Date $)<20]$ & $\begin{array}{c}-0.0433^{* * *} \\
(0.0050)\end{array}$ & $\begin{array}{l}-0.0070 \\
(0.0070)\end{array}$ & \\
\hline $\mathrm{I}[0<($ Sell Date - Purchase Date $)<10]$ & $\begin{array}{c}-0.0425^{\star * *} \\
(0.0047)\end{array}$ & $\begin{array}{l}-0.0032 \\
(0.0067)\end{array}$ & \\
\hline I[(Sell Date - Purchase Date) $==0]$ & $\begin{array}{c}-0.0204^{\star * *} \\
(0.0032)\end{array}$ & $\begin{array}{l}-0.0052 \\
(0.0045)\end{array}$ & \\
\hline $\mathrm{I}[0<($ Sell Date - Purchase Date $)<-10]$ & $\begin{array}{c}-0.0154^{\star * *} \\
(0.0027)\end{array}$ & $\begin{array}{l}-0.0025 \\
(0.0039)\end{array}$ & \\
\hline I $[-20<$ (Sell Date - Purchase Date $)<-10]$ & $\begin{array}{c}0.0053 \\
(0.0037)\end{array}$ & $\begin{array}{c}0.0008 \\
(0.0052)\end{array}$ & \\
\hline I $[-30<$ (Sell Date - Purchase Date $)<-20]$ & $\begin{array}{c}0.0047 \\
(0.0040)\end{array}$ & $\begin{array}{c}0.0054 \\
(0.0058)\end{array}$ & \\
\hline I $[-30<$ (Sell Date - Purchase Date $)<-60]$ & $\begin{array}{l}0.0080^{* *} \\
(0.0034)\end{array}$ & $\begin{array}{l}-0.0033 \\
(0.0049)\end{array}$ & \\
\hline I[-60 < (Sell Date - Purchase Date $)<-180]$ & $\begin{array}{l}0.0123^{* * *} \\
(0.0030)\end{array}$ & $\begin{array}{l}-0.0043 \\
(0.0043)\end{array}$ & \\
\hline I[-180 < (Sell Date - Purchase Date) $<-365]$ & $\begin{array}{c}0.0033 \\
(0.0031)\end{array}$ & $\begin{array}{c}0.0025 \\
(0.0044)\end{array}$ & \\
\hline I[Internal Mover] & & & $\begin{array}{c}0.0634^{* * *} \\
(0.0008)\end{array}$ \\
\hline $\begin{array}{l}\text { Month Fixed Effects } \\
\text { Sample Includes: }\end{array}$ & $\mathrm{x}$ & $\mathrm{x}$ & $\mathrm{x}$ \\
\hline Internal Movers & $x$ & $x$ & $x$ \\
\hline External Movers & & & $\mathrm{x}$ \\
\hline Observations & 180781 & 107618 & 1426192 \\
\hline
\end{tabular}

Standard errors in parentheses

${ }^{* * *} p<0.01,{ }^{* *} p<0.05,{ }^{*} p<0.1$ 